\title{
Phytocannabinoids as novel therapeutic agents in CNS disorders
}

Article

Accepted Version

Hill, A. J., Williams, C. M., Whalley, B. J. and Stephens, G. J. (2012) Phytocannabinoids as novel therapeutic agents in CNS disorders. Pharmacology \& Therapeutics, 133 (1). pp. 79-97. ISSN 0163-7258 doi:

https://doi.org/10.1016/j.pharmthera.2011.09.002 Available at https://centaur.reading.ac.uk/24227/

It is advisable to refer to the publisher's version if you intend to cite from the work. See Guidance on citing.

To link to this article DOI: http://dx.doi.org/10.1016/j.pharmthera.2011.09.002

Publisher: Elsevier

All outputs in CentAUR are protected by Intellectual Property Rights law, including copyright law. Copyright and IPR is retained by the creators or other copyright holders. Terms and conditions for use of this material are defined in the End User Agreement.

\section{www.reading.ac.uk/centaur}

\section{CentAUR}

Central Archive at the University of Reading 
Reading's research outputs online 


\title{
Phytocannabinoids as novel therapeutic agents in CNS disorders
}

\author{
Andrew J Hill ${ }^{1,2}$, Claire M Williams ${ }^{2}$, Benjamin J Whalley ${ }^{1}$ \& Gary J Stephens ${ }^{1}$ \\ ${ }^{1}$ School of Pharmacy and ${ }^{2}$ School of Psychology and Clinical Language Sciences, University of \\ Reading, Whiteknights, Reading, RG6 6UB
}

Address correspondence to: Gary Stephens, University of Reading, PO Box 228, Reading RG6 6AJ, UK. Fax: 0044378 6562. E-mail: g.j.stephens@ reading.ac.uk.

The Cannabis sativa herb contains over 100 phytocannabinoid (pCB) compounds and has been used for thousands of years for both recreational and medicinal purposes. In the past two decades, characterisation of the body's endogenous cannabinoid (CB) (endocannabinoid, eCB) system (ECS) has highlighted activation of central $\mathrm{CB}_{1}$ receptors by the major $\mathrm{pCB}, \Delta^{9}-$ tetrahydrocannabinol $\left(\Delta^{9}-\mathrm{THC}\right)$ as the primary mediator of the psychoactive, hyperphagic and some of the potentially therapeutic properties of ingested cannabis. Whilst $\Delta^{9}$-THC is the most prevalent and widely studied $\mathrm{pCB}$, it is also the predominant psychotropic component of cannabis, a property that likely limits its widespread therapeutic use as an isolated agent. In this regard, research focus has recently widened to include other pCBs including cannabidiol (CBD), cannabigerol (CBG), $\Delta^{9}$ tetrahydrocannabivarin $\left(\Delta^{9}-\mathrm{THCV}\right)$ and cannabidivarin (CBDV), some of which show potential as therapeutic agents in preclinical models of CNS disease. Moreover, it is becoming evident that these non- $\Delta^{9}-\mathrm{THC}$ pCBs act at a wide range of pharmacological targets, not solely limited to $\mathrm{CB}$ receptors. Disorders that could be targeted include epilepsy, neurodegenerative diseases, affective disorders and the central modulation of feeding behaviour. Here, we review pCB effects in preclinical models of CNS disease and, where available, clinical trial data that support therapeutic effects. Such developments may soon yield the first non- $\Delta^{9}$-THC pCB-based medicines.

Key words: cannabinoids, endocannabinoid system, $\mathrm{CB}_{1}$ receptors, electrophysiology, epilepsy, feeding 


\begin{abstract}
Abbreviations
AD, Alzheimer's disease; AED, anti-epileptic drugs; AEA, arachidonylethanolamide; 2-AG, 2arachidonylglycerol; CBC, cannabichromene; CBD, cannabidiol; CBDV, cannabidivarin; CB, cannabinoid; CBG, cannabigerol; CBN, cannibinol; DAGL $\alpha$, diacylglycerol lipase $\alpha$; eCB, endocannabinoid; FAAH, fatty acid amide hydrolase; FST, forced swim test; GPCR, G-proteincoupled receptor; HD, Huntington's disease; 6-OHDA, 6-hydroxydopamine; iNOS, inducible nitric oxide synthase; IN, interneuron; LPS, lipopolysaccharide; MES, maximal electroshock; MAGL, monoacyl glycerol lipase; MS, multiple sclerosis; NO, nitric oxide; NRS, numerical rating scale; PD, Parkinson's disease; pCB, phytocannabinoid; PC, Purkinje cell; rCBF, regional cerebral blood flow; SAD, seasonal affective disorder; SCE, standardised cannabis extract; SPST, stressful public-speaking test; TST, tail suspension test; $\Delta^{9}$-THC, $\Delta^{9}$ tetrahydrocannabinol; $\Delta^{9}-\mathrm{THCV}, \Delta^{9}$ tetrahydrocannabivarin; TRP, transient receptor potential; $\mathrm{TH}+$, tyrosine hydroxylase positive.
\end{abstract}

\title{
Table of contents
}

\section{Introduction}

2. Synthesis and production of phytocannabinoids

3. Phytocannabinoid molecular targets and mechanisms of actions

3.1 The endocannabinoid system (ECS)

3.2 Non-CB receptors and ion channel targets of $\mathrm{pCBs}$

3.3 Neuroprotection and CNS immune function

\section{Effects of phytocannabinoids in CNS disorder, disease and dysfunction}

4.1 Phytocannabinoids in the treatment of epilepsy and hyperexcitability disorders

4.1.1 Historical background

4.1.2 $\Delta^{9}$-tetrahydrocannabivarin $\left(\Delta^{9}-T H C V\right)$ in hyperexcitability

4.1.3 Cannabidiol (CBD) in hyperexcitability

\subsubsection{Summary}

4.2 Phytocannabinoids in the treatment of CNS neurodegenerative diseases

4.2.1 Historical background

4.2.2 Phytocannabinoids in multiple sclerosis (MS) 
4.2.3 Phytocannabinoids in Alzheimer's disease (AD)

4.2.4 Phytocannabinoids in Parkinson's disease (PD)

4.2.5 Phytocannabinoids in Huntington's disease (HD)

4.2.6 Summary

4.3 Phytocannabinoids in affective disorders

4.3.1 Historical background

4.3.2 Phytocannabinoids in anxiety

4.3.3 Phytocannabinoids in depression

4.3.4 Summary

4.4 Phytocannabinoids role in feeding-related disorders

4.4.1 Historical background

4.4.2 Phytocannabinoid standardised cannabis extracts (SCES) in feeding-related disorders

4.4.3 Individual phytocannabinoids in feeding-related disorders

4.4.4 Summary

5. Conclusions 


\section{Introduction}

This review focuses on the emerging potential of phytocannabinoids ( $\mathrm{pCBs}$ ) to act as novel therapeutic agents in CNS disorders, in particular, as assessed by the use of preclinical in vivo animal models of CNS disease and available clinical trial data. Cannabis has been used medicinally and recreationally for thousands of years with early documentation of medicinal use in Chinese pharmacopoeias (Li \& Lin, 1974) and the Indian Atharva Veda which accords cannabis status as one of five sacred plants (Touw, 1981). Early texts on herbal medicines were summarized by Dioscorides in $\sim 60$ A.D. and by Galen, who wrote of cannabis in the $2^{\text {nd }}$ century A.D. in his De facultatibus alimentorum, "The leaves of this plant cure flatus - some people squeeze the fresh (seeds) for use in ear-aches. I believe that it is used in chronic pains". Cannabis appeared in the 1788 New England Dispensatory, which retained large elements of Dioscorides herbal pharmacopoeia. Work of the $19^{\text {th }}$ century Irish physician, William O'Shaughnessy, introduced medicinal use of cannabis to the UK (O'Shaughnessy, 1840), benefiting from the ascribed analgesic, anti-inflammatory, anti-emetic and anti-convulsant properties of the plant. However, medicinal use of cannabis fell out of favour in the early $20^{\text {th }}$ century, largely due to concerns about psychoactivity and effects on behaviour, motor coordination and memory and learning; such concerns lead to cannabis being removed from the British Pharmacopoeia in 1932 (Ashton, 2001; Kalant, 2001; Robson, 2001). However, it was still possible for UK physicians to prescribe cannabis for specific medicinal uses up to 1973, until prohibition by the Misuse of Drugs Regulation; in the current iteration of this Act (1985), cannabis is classified in Schedule 1, meaning that therapeutic use is effectively prohibited (Moffat, 2002).

Despite these restrictions, interest in the pharmacology and potential therapeutic use of pCBs was engendered by the isolation of $\Delta^{9}$-THC and the subsequent discovery of other pCBs (Gaoni \& Mechoulam, 1971; Mechoulam, 2005). Thereafter, the development of synthetic CB receptor ligands, such as Pfizer's CP55,940 in the 1980s, led to the identification of specific $\Delta^{9}$ THC binding sites in the human CNS (Herkenham et al., 1990) and the identification and cloning of the first $\mathrm{CB}$ receptor, $\mathrm{CB}_{1}$ (Matsuda et al., 1990). These findings contributed to the discovery of the endocannabinoid (eCB) system (ECS) (a term introduced by Di Marzo \& Fontana, 1995), which comprises the cannabinoid (CB) receptors, eCBs as their endogenous 
ligands and the proteins responsible for eCB synthesis and degradation. Shortly thereafter, a second, principally peripheral, cannabinoid $\mathrm{CB}_{2}$ receptor was identified in 1993 (Munro et al., 1993). Around the same time, arachidonic acid-derived, endogenous CB receptor ligands were identified, with the discovery of arachidonylethanolamide (AEA; Devane et al., 1992) and 2arachidonylglycerol (2-AG) (Mechoulam et al., 1995; Sugiura et al., 1995). The first eCB degrading enzyme to be cloned was fatty acid amide hydrolase (FAAH; Cravatt et al., 1996), with a number of further degradation and synthetic enzymes being identified shortly afterwards (Patricelli \& Cravatt, 2001); these enzymes have become a major target for therapeutic manipulation (Di Marzo, 2008, 2009). The discovery and characterisation of the ECS subserved a resurgence of interest in the pharmacological effects of the individual pCBs (Izzo et al., 2009; Pertwee, 2008).

Despite the therapeutic potential afforded by the discovery of the ECS, licensed pCBbased medicines have largely been restricted to the use of $\Delta^{9}$-THC in a subset of chronically ill patients. Synthetically produced $\Delta^{9}$-THC and its analogues are used clinically as dronabinol and nabilone, both used for attenuation of cancer chemotherapy-induced nausea and vomiting and appetite stimulation in HIV/AIDS patients. The widespread use of $\Delta^{9}$-THC is limited by psychoactivity and the associated abuse potential. $\Delta^{9}$-THC is a partial agonist at $\mathrm{CB}_{1}$ receptors whilst, by contrast, the anti-obesity agent, rimonabant, was the first clinically licensed $\mathrm{CB}_{1}$ receptor antagonist. However, as a result of psychiatric side effects (depression and suicidality) reported following usage of higher doses (Christensen et al., 2007), rimonabant sales were suspended in 2008. Sativex (an approximately 1:1 mixture of $\Delta^{9}$-THC:CBD) is the first medicine derived from whole cannabis plant extracts to be licensed (at present in the UK, Canada, Spain, Germany, Denmark and New Zealand); specifically, to treat pain and spasticity in multiple sclerosis (MS) patients (Barnes, 2006; Perras, 2005). Most pertinently, the introduction of Sativex provided a precedent for the licensed therapeutic use of pCBs, a theme that will be further investigated here. The combination of CBD and $\Delta^{9}$-THC in Sativex is considered to reduce unwanted effects of $\Delta^{9}$-THC (Russo \& Guy, 2006), most likely by CBD inhibiting the metabolism of $\Delta^{9}-\mathrm{THC}$ to the more psychoactive $11-\mathrm{OH}-\Delta^{9}-\mathrm{THC}$ (Bornheim \& Grillo, 1998), and there is evidence that CBD can oppose $\Delta^{9}$-THC effects in vivo (Malone et al., 2009; Vann et al., 2008). Thus, Sativex is an important development as it reduces $\Delta^{9}$-THC 
central actions to produce a drug which is more tolerable and less prone to abuse (Schoedel et $a l ., 2011)$. In this regard, it is also possible that $\Delta^{9}$-THC efficacy could be enhanced by 'entourage' effects of other pCBs present in the $\Delta^{9}$-THC and CBD extracts of which Sativex is comprised (Russo, 2011). Overall, the investigation of alternative, non- $\Delta^{9}$-THC pCBs which lack psychotropic effects, but retain pharmacological activity, and the elucidation of their mechanisms of action has increasingly become a focus of the pharmaceutical industry and their potential to combat CNS disease is the major focus of this review.

\section{Synthesis and production of phytocannabinoids}

pCBs are lipid-soluble chemicals present in the resin secreted from trichomes that are abundantly produced by female plants of the Cannabis sativa herb. It is worth highlighting that pCBs are not so named because they share a common pharmacological target site or mechanism of action to eCBs and synthetic $\mathrm{CBs}$, but due to their shared chemical structure. Within the plant, pCBs are synthesised from fatty acid precursors via a series of transferase and synthase enzymes (Figure 1). The two major pCBs, $\Delta^{9}-\mathrm{THC}$ and $\mathrm{CBD}$, are derived from a common synthetic precursor, cannabigerol (CBG). From a pharmacochemical perspective, whilst $\Delta^{9}$-THC and CBD have pentyl side chains, major homologues are $\Delta^{9}-$ tetrahydrocannabivarin $\left(\Delta^{9}-\mathrm{THCV}\right)$ and cannabidivarin (CBDV) respectively, with propyl sidechains, derived from cannabigerovarin (CBGV). As discussed below, despite only small differences in chemical structure, these compounds appear to exhibit markedly different pharmacological properties. Other pCBs, such as cannabinol $(\mathrm{CBN})$, are considered to be oxidation products. All pCBs are uniquely found in cannabis, with the total number of identified pCBs currently reported as over 100 (together with over 500 non-cannabinoid constituents; Elsohly \& Slade, 2005; Mehmedic et al., 2010). The plant can be genetically manipulated to alter the relative ratios of the pCBs produced. Whilst this exploitable feature has been capitalised upon by the recreational drug market as a means to increase $\Delta^{9}$-THC yields, it is only more recently that the approach has been successfully used to develop a legitimate medicinal product. Thus, it is possible to use solely horticultural techniques to produce cloned plants ('chemovars') which are uniformly enriched in different, specific pCBs (de Meijer et al., 2003). Analogous to pharmaceutical synthesis of drug material, these processes follow FDA 
botanical guidelines (Food and Drug Administration, 2004) to transform a raw material into a botanical drug substance as an active pharmaceutical ingredient, which can then be formulated into a botanical drug product, such as the standardised cannabis extracts (SCEs) used in Sativex. Importantly, modulation of the ratio of specific pCBs in different SCEs may not only offer therapeutic potential dependent on the nature of the target disease, but also provide a viable intellectual property model to justify pharmaceutical industry development of cannabisbased medicines.

\section{Phytocannabinoid molecular targets and mechanisms of actions}

\subsection{The endocannabinoid system (ECS)}

The detailed characterisation of the ECS, including the molecular determination of $\mathrm{CB}$ receptors and the metabolic pathways and actions of eCBs, initially provided a useful framework to discuss pCB actions. CB receptor activity can be modulated directly by ligand binding, or indirectly, via modulation of eCB levels (for example by enzyme inhibition). $\mathrm{CB}_{1}$ and $\mathrm{CB}_{2}$ receptors are seven-transmembrane spanning proteins of the rhodopsin G-protein-coupled receptor (GPCR) family A, sharing $44 \%$ sequence identity overall with $68 \%$ identity in their transmembrane domains (Munro et al., 1993; Pertwee et al., 2010). The pertussis toxin-sensitive nature of $\mathrm{CB}$ receptor-induced adenylyl cyclase inhibition suggested a predominant coupling to inhibitory $\mathrm{G}_{\mathrm{i} / \mathrm{o}}$ subunits (Felder et al., 1993). Within the $\mathrm{CNS}, \mathrm{CB}_{1}$ receptors are largely localized to presynaptic terminals, particularly in the cerebral cortex, hippocampus, cerebellum and basal ganglia, with little evidence of postsynaptic expression (Herkenham et al., 1990; Tsou et al., 1998). Activation of presynaptic $\mathrm{CB}_{1}$ receptors, via the retrograde release of eCBs produced by postsynaptic cells following periods of sustained excitation (Alger \& Kim, 2011), causes a inhibition of neurotransmitter release and dynamically modulates both excitatory and inhibitory neuronal activity in the CNS (Chevaleyre et al., 2006; Ma et al., 2008; Guggenhuber et al., 2010). Recent studies have identified $\mathrm{CB}_{2}$ protein and mRNA at sites in the CNS (Van Sickle et al., 2005; Onaivi et al., 2006). $\mathrm{CB}_{2}$ receptors are expressed in the CNS on astrocytes, microglia and cerebromicrovascular endothelial cells (Golech et al., 2004; Nunez et al., 2004; Rivers \& Ashton, 2010) and such expression could play a role in pathogenesis and treatment of 
conditions involving neuroinflammation and neurodegeneration (Arevalo-Martin et al., 2008; Cabral \& Griffin-Thomas, 2009).

It is becoming apparent that pCBs exhibit a considerable range of affinities for the $\mathrm{CB}_{1}$ receptor (Figure 2; Kreitzer \& Stella, 2009; Pertwee, 2008; Pertwee et al., 2010). $\Delta^{9}-\mathrm{THC}$ is believed to exert the majority of its actions in the CNS as a partial agonist at $\mathrm{CB}_{1}$ receptors (Howlett, 2002). Amongst other pCBs, $\Delta^{9}$-THCV is one of the few compounds known to exert direct and relatively potent effects at $\mathrm{CB}$ receptors, leading to its description as a $\mathrm{CB}_{1}$ antagonist (although with evidence of $\mathrm{CB}_{1}$ agonist properties at higher doses (>10 mg/kg in vivo)) and, also, a potent $\mathrm{CB}_{2}$ receptor partial agonist (Thomas et al., 2005; Dennis et al., 2008; Ma et al., 2008; Pertwee, 2008; Bolognini et al., 2010). Interestingly, CBD shows only low CB receptor binding affinity (Bisogno et al., 2001; Pertwee, 2008; Jones et al., 2010; Figure 2), but has been shown to antagonise the action of synthetic $\mathrm{CB}$ ligands at $\mathrm{CB}_{1}$ and $\mathrm{CB}_{2}$ receptors (Pertwee et al., 2002; Thomas et al., 2007). In general, current knowledge for actions of other pCBs at CB receptors remains incomplete; however, $\mathrm{CBG}$ has been reported to exhibit only low $\mathrm{CB}$ receptor potency (Figure 2; Cascio et al., 2010), but antagonises the effects of $\mathrm{CB}_{1}$ ligands in $\left[{ }^{35} \mathrm{~S}\right] \mathrm{GTP} \gamma \mathrm{S}$ binding assays (Cascio et al., 2010). Moreover, recent pharmacological evidence has shown that the $\mathrm{CB}_{1}$ receptor contains an allosteric binding site (Price et al., 2005; Horswill et al., 2007) and the allosteric $\mathrm{CB}_{1}$ receptor antagonist, PSNCBAM-1 exerts agonist-dependent effects on inhibitory synaptic transmission in the CNS (Wang et al., 2011). The identification of an allosteric $\mathrm{CB}_{1}$ site promises to drive the characterisation and development of novel probes and drug candidates, although any potential for pCBs to act via such sites is not known as yet. Overall, whilst these studies demonstrate that selected pCBs (i.e. $\Delta^{9}$-THC and $\Delta^{9}$-THCV) exert effects via direct interaction with $\mathrm{CB}$ receptors, other $\mathrm{pCBs}$ thus far investigated exhibit an alternative, but potentially therapeutically exploitable, pharmacology (Izzo et al., 2009).

More recent evidence has revealed that $\mathrm{pCBs}$ can exert effects via modulation of $\mathrm{eCB}$ tone in the CNS. The principal targets so far identified are the 2-AG biosynthetic enzyme, diacylglycerol lipase $\alpha$ (DAGL $\alpha)$, and the catabolic enzymes, FAAH and monoacyl glycerol lipase (MAGL), predominantly responsible for AEA and 2-AG hydrolysis, respectively (Di Marzo et al., 2005). A number of prominent non- $\Delta^{9}$-THC pCBs show micromolar potency as ECS enzyme inhibitors in vitro: CBDV inhibits DAGL $\alpha$, CBD inhibits FAAH whilst CBG and 
cannabichromene (CBC) inhibit MAGL (Watanabe et al., 1996; Rakhshan et al., 2000; Bisogno et al., 2001; De Petrocellis et al., 2011). In a related fashion, micromolar concentrations of CBG, CBC, CBDV and CBN all inhibit cellular uptake of AEA (De Petrocellis et al., 2011). Whilst the functional effects of $\mathrm{pCBs}$ on $\mathrm{eCB}$ tone and their pharmacological relevance remain to be fully determined, this evidence suggests that $\mathrm{pCB}$ effects in the CNS are not limited to components of the ECS and such distinctions are discussed below.

\subsection{Non-CB receptors and ion channel targets of $p C B s$}

In addition to effects on the ECS, evidence arising from pharmacological experiments in recombinant cell lines and $\mathrm{CB}$ receptor knock-out animals strongly supports $\mathrm{pCB}$ actions at alternative, non-CB receptor sites. Orphan GPCRs, most notably GPR55 and GPR119, have been identified as potential novel $\mathrm{CB}$ receptors on the basis of affinity for some $\mathrm{CB}$ ligands (Pertwee, 2007; Ross, 2009; Pertwee et al., 2010). However, it is not yet clear whether GPR55 is a bona fide $\mathrm{CB}$ receptor, as it possesses low sequence homology to $\mathrm{CB}_{1}$ and $\mathrm{CB}_{2}$ and the endogenous phospholipid, lysophosphatidylinositol, also has affinity for the receptor (Nevalainen \& Irving, 2010; Sharir \& Abood, 2010). There are, thus far, limited reports of pCB activity at GPR55; for example, $\Delta^{9}$-THC has a weak agonist effect, whilst reports of CBD as a GPR55 antagonist appear to be largely assay-dependent (Pertwee et al., 2010).

An interesting emerging concept is that $\mathrm{pCBs}$ can also activate non-CB metabotropic GPCRs. In particular, CBD has been widely reported to act as a $5-\mathrm{HT}_{1 \mathrm{~A}}$ agonist (Russo et al., 2005; Magen et al., 2010; Ledgerwood et al., 2011) and also to have actions sensitive to adenosine A2A receptor antagonists (Magen et al., 2009). Another recent study has shown that $\mathrm{CBG}$ is an agonist at $\alpha 2$-adrenoceptors and an antagonist at $5-\mathrm{HT}_{1 \mathrm{~A}}$ receptors (Cascio et al., 2010). It is also becoming clear that $\mathrm{pCBs}$ have the potential to affect neuronal excitability via the modulation of ligand-gated and voltage-gated ion channels (Pertwee, 2008; Pertwee et al., 2010). In particular, recent studies have highlighted the effects of a number of pCBs, including $\mathrm{CBD}, \mathrm{CBG}, \mathrm{CBC}$ and $\mathrm{CBN}$, at different transient receptor potential (TRP) (ligand-gated nonselective cation) channels. CBD has been widely reported to activate TRPV1 and TRPV2 channels (Costa et al., 2004; De Petrocellis et al., 2008; Qin et al., 2008); interestingly, TRPV1 co-localises with $\mathrm{CB}_{1}$ receptors in mouse brain (Cristino et al., 2006). More recently, CBG, 
CBGV and $\Delta^{9}$-THCV have also been shown to activate TRPV1 channels (De Petrocellis et al., 2011). Similarly, $\Delta^{9}$-THC, CBD, CBGV, CBG, $\Delta^{9}-\mathrm{THCV}$ and CBDV have all been shown to activate rat TRPV2 channels (De Petrocellis et al., 2011). pCB effects at TRPV1 and TRPV2 channels typically manifest at low micromolar concentrations, which does question, but not exclude, their pharmacological relevance; for example, reported actions included channel desensitization, akin to the proposed therapeutic action for agonists such as capsaicin. CBD, $\mathrm{CBC}$, and $\mathrm{CBN}$ are more potent (nanomolar concentration) agonists at rat TRPA1 channels and also desensitise the channel (De Petrocellis et al., 2011). CBD, CBG, CBN, $\Delta^{9}$-THCV, CBDV and CBGV (at low micromolar concentrations) all also act as antagonists at rat TRPM8 channels (De Petrocellis et al., 2011). CBD has also been demonstrated to act at ligand-gated receptors, being a putative allosteric inhibitor of 5-HT $\mathrm{H}_{3 \mathrm{~A}}$ receptors (Yang et al., 2010) and an allosteric and direct activator of inhibitory glycine receptors (Ahrens et al., 2009; Foadi et al., 2010). There is growing evidence that synthetic CBs and eCBs can modulate voltagedependent $\mathrm{Ca}^{2+}, \mathrm{K}^{+}$and $\mathrm{Na}^{+}$channels (Demuth \&Molleman, 2006; Oz, 2006; Pertwee et al., 2010); at present, evidence for similar pCB actions at ion channels is limited. However, $\Delta^{9}-$ THC and CBD have recently been shown to inhibit Cav3.1, Cav3.2 and Cav3.3 (T-type) $\mathrm{Ca}^{2+}$ channels (Ross et al., 2008). Therefore, both ligand-gated and voltage-dependent ion channels may be targeted by $\mathrm{pCBs}$ and it will be important to augment such studies using in vitro electrophysiology to determine the functional effects of pCBs on neuronal excitability and whether such effects are seen at pharmacologically relevant concentrations.

\subsection{Neuroprotection and CNS immune function}

pCBs are known to protect neurons from neurotoxic stimuli or neurodegeneration via a range of properties which may include ligand action at $\mathrm{CB}$ receptors, innate antioxidant properties and effects on the CNS immune system. $\Delta^{9}$-THC has been shown to possess $\mathrm{CB}_{1}$-dependent neuroprotective effects in excitotoxicity assays in vitro (Abood et al., 2001; Gilbert et al., 2007) and in vivo (Chen \& Buck, 2000; van der Stelt et al., 2001; El-Remessy et al., 2003; Zani et al., 2007). However, several studies have highlighted CB receptor-independent mechanisms by which $\Delta^{9}$-THC and other pCBs can protect neurons. Most clearly described is the antioxidant capacity of pCBs. A study in 1998 first highlighted the $\mathrm{CB}_{1}$ receptor-independent antioxidant 
properties of $\Delta^{9}$-THC and CBD (Hampson et al., 1998), demonstrating their ability to protect rat cortical neurons from glutamate receptor-mediated excitotoxicity, which is known to be mediated by reactive oxygen species. El-Remessy et al. (2003) showed that both $\Delta^{9}$-THC and CBD protected rat retinal neurons against NMDA-induced neurotoxicity in vivo, decreasing levels of peroyxnitrite and associated oxidative stress-related compounds.

pCBs are also able to modulate immune cells and the production of immune factors in the CNS in experimentally-induced models of neurodegenerative disorders. The primary immune cells in the CNS are microglia which provide support to neural cells; in neurodegenerative diseases, microglia are co-localised to sites of neuronal death (Ramirez et al., 2005; Lull \& Block, 2010). Agonism of $\mathrm{CB}_{2}$ receptors on microglia attenuates their further activation (Carrier et al., 2004; Kreitzer \& Stella, 2009; Stella, 2010), limiting ability of microglia to release proinflammatory agents including tumour necrosis factor $\alpha$ and nitric oxide (NO) (Ehrhart et al., 2005; Ramirez et al., 2005). Correspondingly, the agonist properties of both $\Delta^{9}$-THC and $\Delta^{9}$ THCV at $\mathrm{CB}_{2}$ receptors have been implicated in neuroprotection in vivo (Tourino et al., 2010; Garcia et al., 2011). CBD has also been shown to be anti-inflammatory by limiting ATP-induced increases in intracellular $\mathrm{Ca}^{2+}$ levels and NO production in cultured microglial cells (MartinMoreno et al., 2011). An anti-inflammatory effect of CBD was also observed in lipopolysaccharide (LPS)-injected mice due to inhibition of adenosine uptake (Carrier et al., 2006); a similar effect was seen in vitro and in rat retina insulted by LPS (Liou et al., 2008). Production of pro-inflammatory cytokines by LPS-stimulated cultured microglial cells was

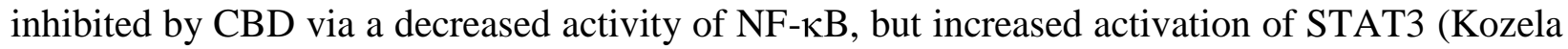
et al., 2010). Additionally, CBD decreased inducible nitric oxide synthase (iNOS) expression and TNF $\alpha$ levels in a mouse model of LPS-induced inflammation (Ruiz-Valdepenas et al., 2011).

In summary, it is clear that pCBs exhibit a range of apparently neuromodulatory, neuroprotective, anti-oxidant and anti-inflammatory properties, including effects on biochemical pathways that could complement their effects on receptors, ion channels and enzymes to achieve an overall therapeutic aim. The utility of such effects is discussed hereafter in an examination of pCB effects in animal models of CNS disease and human clinical trials. 


\section{Effects of phytocannabinoids in CNS disorder, disease and dysfunction}

\subsection{Phytocannabinoids in the treatment of epilepsy and hyperexcitability disorders}

\subsubsection{Historical background}

Cannabis has played a historical role in the treatment of hyperexcitability disorders, a prominent example being epilepsy, where the first evidence of therapeutic use was attributed to the Arabic scholar al-Mayusi in 1100AD (Lozano, 2001), although additional evidence to support such use can be found in both Ayurvedic and Islamic medicine (Russo, 2005; Russo 2007). Cannabis use was again noted in the $15^{\text {th }}$ century, when the historian Ibn al-Badri wrote that when "the epileptic son of the caliph's chamberlain" was treated with cannabis "it cured him completely, but he became an addict who could not for a moment be without the drug" (Mechoulam, 1986), a predictable consequence given the chronic, progressive nature of epilepsy. Thereafter, it was not until after William O'Shaughnessy successfully treated seizures in an infant using cannabis tincture (O'Shaughnessy, 1840) that further reports emerged describing attempts to use cannabis to treat seizures (McMeens, 1856, 1860; Reynolds, 1868).

In the 1970s, effects of several common cannabis constituents on seizure states were further examined using the maximal electroshock (MES) model (Karler et al., 1973; Karler et al., 1974b; Turkanis et al., 1974). These early studies revealed an order of potency of $\Delta^{9}$ THC $>C B D>C B N$ although, interestingly, the authors asserted that CBD had the greatest protective index, comparable to the, then widely used, anticonvulsant phenobarbital (for review, see Karler \& Turkanis, 1981; Karler \& Turkanis, 1976). These studies supported a number of small-scale human trials, individual case studies and surveys that investigated herbal cannabis and isolated pCB use for seizure control (Table 1). Whilst these studies stimulated a limited number of pre-clinical investigations (Chiu et al., 1975; Karler et al., 1974a; Smiley et al., 1976; Thomson \& Turkanis, 1973; Turkanis et al., 1977; Turkanis \& Karler, 1975; Turkanis \& Karler, 1981a; Turkanis \& Karler, 1987; Turkanis et al., 1991; Turkanis et al., 1979), the complex nature of epilepsy and the diverse model- and species-specific effects of cannabis (and individual $\mathrm{pCBs}$ ) rendered the elucidation of mechanisms of action difficult, particularly in the case of $\Delta^{9}$-THC, upon which attention had been largely focussed (Martin \& Consroe, 1978; Consroe \& Fish, 1980). 
The renewed interest in potential therapeutic applications of pCBs included investigations using in vitro models of epileptiform activity (Wilkinson et al., 2003; Whalley et al., 2004) and, subsequently, in vivo models of seizure. $\Delta^{9}$-THC clearly affects seizure states and susceptibility in preclinical models (Lutz, 2004; Boggan et al., 1973) via well-known effects at central $\mathrm{CB}_{1}$ receptors (Shen \& Thayer, 1999). However, $\Delta^{9}$-THC (and other $\mathrm{CB}_{1}$ agonists) often exhibit contradictory pro- and anti-convulsant effects in clinical cases (Table 1) and preclinical models (Karler \& Turkanis, 1980; Turkanis \& Karler, 1981b; Turkanis \& Karler, 1982; Consroe \& Mechoulam, 1987; Wallace et al., 2001; Fish et al., 1983). Together with psychotropic side effects, such contradictory effects likely limit or prohibit $\Delta^{9}$-THC's widespread therapeutic use as an isolated agent. However, many surveys continue to report medicinal cannabis use for the control of seizures, which lends credence to an overall conclusion that the presence of $\Delta^{9}$-THC in SCEs per se does not necessarily represent a de facto pro-convulsant risk. Moreover, in some clinical cases (Table 1), $\Delta^{9}$-THC at higher doses can be an effective anticonvulsant, but is limited by extensive psychoactive side-effects. Overall, whilst the variability of $\Delta^{9}$-THC's effects may represent a limiting factor, growing evidence supports attenuation of undesirable $\Delta^{9}$-THC effects by pCB- and non-pCB components of cannabis (Russo, 2011), so improving its therapeutic index and legitimising the case-by-case use of $\Delta^{9}$-THC-based medicines (e.g. 'medical marijuana') against seizures, as is currently the case in Canada and some US states.

\subsection{2 $\Delta^{9}$-tetrahydrocannabivarin $\left(\Delta^{9}-T H C V\right)$ in hyperexcitability}

$\Delta^{9}$-THCV has demonstrated interesting potential for use in the treatment of hyperexcitability states. Following identification and characterisation of $\Delta^{9}-\mathrm{THCV}$ as a $\mathrm{CB}_{1}$ receptor antagonist (Thomas et al., 2005; Dennis et al., 2008), the increase of inhibitory synaptic transmission in cerebellar brain slices represented the first description of functional $\Delta^{9}$-THCV effects in the CNS (Ma et al., 2008). In the latter study, $\Delta^{9}$-THCV $(5-58 \mu \mathrm{M})$ significantly increased GABAergic transmission at interneuron-Purkinje cell (IN-PC) synapses in patch clamp electrophysiological recording; complementary use of multi-electrode array (MEA) recording demonstrated that $\Delta^{9}$-THCV significantly reduced spontaneous unit and multi-unit PC spike firing (Figure 3; Ma et al., 2008). $\Delta^{9}$-THCV modulated the effects of the $\mathrm{CB}$ agonist 
WIN55,212-2 and $\Delta^{9}$-THCV actions were abolished by the $\mathrm{GABA}_{A} \mathrm{R}$ antagonist, bicuculline. Overall, these data were consistent with $\Delta^{9}$-THCV antagonising $\mathrm{CB}_{1}$ receptors at IN-PC presynapses to increase inhibitory neurotransmission (either via a blockade of eCB action or by attenuation of constitutive $\mathrm{CB}_{1}$ activity) leading to a reduction in $\mathrm{PC}$ excitation. The ability of $\Delta^{9}$-THCV to modulate PC output contrasts with the well-known adverse (partial) agonist effects of $\Delta^{9}$-THC, which induces deficits in motor coordination in vivo (DeSanty \& Dar, 2001a; DeSanty \& Dar, 2001b; Patel \& Hillard, 2001), a reported effect of cannabis intoxication. From the perspective of hyperexcitability states, the effects of $\Delta^{9}-\mathrm{THCV}$ in increasing inhibition in the cerebellum is consistent with a desirable pharmacological profile for use in spinocerebellar ataxias, a progressive and presently pharmacologically untreatable group of hyperexcitability disorders (Paulson, 2009), although pre-clinical in vivo animal studies in this specific therapeutic area have yet to be undertaken.

More recently, $\Delta^{9}$-THCV was reported to exhibit in vitro anti-epileptiform and in vivo anticonvulsant properties (Hill et al., 2010a). In this study, $\Delta^{9}$-THCV ( $\left.>20 \mu \mathrm{M}\right)$ significantly reduced burst complex incidence and the amplitude and frequency of paroxysmal depolarizing shifts (PDSs) induced by use of $\mathrm{Mg}^{2+}$-free media (which activates excitatory glutamatergic NMDA receptors) in piriform cortical brain slices; $\Delta^{9}-\mathrm{THCV}$ also inhibited the propagation of this epileptiform activity. This investigation also showed that pre-incubation of piriform cortical slices with $10 \mu \mathrm{M} \Delta^{9}$-THCV significantly reduced neuronal excitability in response to $\mathrm{Mg}^{2+}$-free media, consistent with the hypothesis that exposure to $\Delta^{9}-\mathrm{THCV}$ may be prophylactic in preventing hyperexcitability. In the pentylenetetrazole model of acute generalised seizures, $\Delta^{9}$-THCV $(0.25 \mathrm{mg} / \mathrm{kg})$ significantly reduced seizure incidence, although failing to affect other commonly employed seizure measures (Hill et al., 2010a). It has been shown recently that in vivo seizure states may be disrupted as a result of a $\mathrm{CB}_{1}$ agonistmediated desynchronisation of pathological neuronal firing (Mason \& Cheer, 2009), similar desynchronisation could also hold true for $\mathrm{CB}_{1}$ antagonist-mediated blockade of eCB tone; such a hypothesis is consistent with known $\Delta^{9}$-THCV effects upon the propagation of epileptiform activity (Hill et al., 2010a).

Overall, although the concept of presynaptic $\mathrm{CB}_{1}$ receptor-mediated inhibition of excitatory neurotransmitter release being consistent with anti-epileptiform effects is intuitively 
clear (Lutz, 2004), a mechanism underlying anticonvulsant $\Delta^{9}$-THCV effects, alongside other confirmatory and contradictory reports of synthetic $\mathrm{CB}_{1}$ antagonist effects in seizure models (Echegoyen et al., 2009; Kozan et al., 2009), is not immediately apparent. However, when a preferential CB receptor ligand effect is considered, such as that described above for inhibitory IN-PC synapses in the cerebellum (Ma et al., 2008) or excitatory terminals in the hippocampus (Monory et al., 2006), it becomes clear that effects on neuronal excitability obtained via $\mathrm{CB}_{1}$ modulation are likely to be highly dependent upon the sub-population of neurons (i.e. inhibitory or excitatory) preferentially affected (Lutz, 2004).

\subsubsection{Cannabidiol (CBD) in hyperexcitability}

CBD remains the only isolated, non- $\Delta^{9}-$ THC $\mathrm{pCB}$ to have been investigated for anticonvulsant effects in human subjects to date (Table 1). As early as 1977, CBD effects upon seizure states in animals were investigated using MES and audiogenic seizures and compared with those of standard anti-epileptic drugs (AEDs) including phenytoin, phenobarbital, carbamazepine, and ethosuximide (Consroe \& Wolkin, 1977a). CBD (>100 mg/kg) administered alone was an effective anticonvulsant in both seizure models, but had differential effects when coadministered with standard AEDs, enhancing the anticonvulsant effects of phenytoin or phenobarbital, but diminishing the effects of chlordiazepoxide, clonazepam, trimethadione or ethosuximide (Consroe \& Wolkin, 1977a; Consroe \& Wolkin, 1977b). A potential advantage of CBD is that, unlike $\Delta^{9}$-THC, no evidence of contradictory central excitatory or pro-convulsant effects exists (Chiu et al., 1979). In electrically kindled limbic seizures in rats, CBD (0.3-3 $\mathrm{mg} / \mathrm{kg}$ ) raised epileptic after-discharge threshold in a manner consistent with the known effects of phenytoin in this model, but, in common with the effects of ethosuximide, also decreased after-discharge amplitude, duration and propagation (Turkanis et al., 1979). It is notable that, compared to phenytoin and ethosuximide, the authors concluded that " $C B D$ was the most efficacious of the drugs tested against limbic ADs [after-discharges] and convulsions”. CBD had a selective depressant effect upon evoked cortico-limbic responsiveness in non-epileptic states (Turkanis \& Karler, 1981a). CBD (60 mg/kg) had no discernible effect in rats rendered chronically epileptic by cortical implantation of cobalt, which manifests as partial seizures with secondary generalisation (Colasanti et al., 1982), whilst $\Delta^{9}$-THC was found to exert a short 
term ( 1 day) anticonvulsant effect. It is however noteworthy that cobalt-induced seizures share many common features with human absence seizures (Loscher, 1997) and, as such, have little in common with seizure models in which CBD exerts a significant anticonvulsant effect. Such model-specific effects were also exemplified using a battery of acute models of seizures induced by agents that included MES, 3-mercaptoproprionic acid, picrotoxin, isonicotinic acid hydrazine, bicuculline, pentylenetetrazole and strychnine (Consroe et al., 1982). Here, CBD $(50-400 \mathrm{mg} / \mathrm{kg}$ with most notable effects occurring at $>100 \mathrm{mg} / \mathrm{kg}$ ) was equally effective in the MES and all GABA inhibition-based models, but entirely ineffective against strychnineinduced convulsions.

More recently, CBD effects upon chemically-induced epileptiform activity in acute hippocampal brain slices have been described (Jones et al., 2010). Here, CBD significantly reduced measures of spontaneous epileptiform activity induced either by use of $\mathrm{Mg}^{2+}$-free media, or by the application of the $\mathrm{K}^{+}$channel blocker, 4-aminopyridine. In the $\mathrm{Mg}^{2+}$-free model, CBD $(100 \mu \mathrm{M})$ decreased epileptiform local field potential burst amplitude and duration. In the 4-aminopyridine model, CBD $(100 \mu \mathrm{M})$ decreased burst amplitude in CA1 only, burst duration in CA3 and dentate gyrus, and burst frequency in all regions. The same report also recapitulated the previous investigation of $\mathrm{CBD}$ effects upon pentylenetetrazole-induced, acute, generalised seizures (Consroe et al., 1982) and found that CBD (100 mg/kg) significantly decreased mortality and the incidence of the most severe seizure states. Finally, in this study, $\mathrm{CBD}$ was shown to exhibit only low affinity for $\mathrm{CB}_{1}$ receptors in radioligand binding studies and no agonist activity in GTP $\gamma \mathrm{S}$ binding assays, supporting a $\mathrm{CB}_{1}$ receptor independent mechanism of anticonvulsant action (Jones et al., 2010; see also Figure 2).

Taken together, CBD exhibits the most reliable anticonvulsant effects of currently tested pCBs. Moreover, in contrast to clinically used anticonvulsants, CBD exhibits no neurotoxic or motor side-effects as assessed by standard rotarod tests (Consroe et al., 1981; Martin et al., 1987). Overall, recent data more fully supports the proposal for CBD potential in the treatment of grand mal, cortical focal, partial, but not absence seizures. In this regard, CBD exhibits a potential useful polypharmacology that may benefit modulation of neuronal excitability (Figure 4). In addition to the epilepsy-specific actions described above, CBD has been shown to reduce intracellular $\mathrm{Ca}^{2+}$ levels in hippocampal neurons under conditions modelling increased 
excitability (Ryan et al., 2009). Such actions occur via an inhibitory action on mitochondria $\mathrm{Ca}^{2+}$ stores and are consistent with CBD possessing further useful actions to reduce hyperexcitability in the CNS.

\subsubsection{Summary}

Overall, $\Delta^{9}$-THC effects in hyperexcitability disorders can be unpredictable and, based on the extant evidence, effects are likely to be specific to the disorder and the individual which is, given $\Delta^{9}$-THC's psychoactive effects and the idiopathic and/or cryptogenic natures of most epilepsies, unsurprising. This, together with notable side effects, limits $\Delta^{9}$-THC's widespread therapeutic use, although sufficient case studies have reported apparent benefit and so prevent the drawing of a single definitive conclusion applicable to all epilepsies. We have used complementary in vitro electrophysiological techniques to provide the first descriptions of non-

$\Delta^{9}$-THC pCB effects in hyperexcitability in the CNS; in particular, effects of $\Delta^{9}$-THCV and CBD have been translated into preclinical in vivo seizure models and shown to possess therapeutic potential. Whilst $\Delta^{9}$-THCV shows some promise in this regard, its clinical utility may be limited to pathophysiological conditions associated with $\mathrm{CB}_{1}$ receptors preferentially located on inhibitory synapses. By contrast, there is clearly compelling evidence to support further investigation of CBD effects in human hyperexcitability states, either as an adjunct or standalone treatment. More broadly, whilst $\Delta^{9}-\mathrm{THCV}$ and CBD's effects in seizure models cast new light upon the potential therapeutic use of cannabis constituents for the treatment of hyperexcitability disorders, it is notable that they still represent a minority of the pCBs present in cannabis. Consequently, further studies are required to assess whether other, as yet uninvestigated, $\mathrm{pCBs}$ modulate seizure activity from both the perspective of AED development and risks associated with cannabis use (Wilkinson et al., 2003; Hill et al., 2010b). In the near future, it will be important to extend investigations in disease models to fully determine their potential as therapeutic agents in their own right or their use as a structural basis for rational drug development, and then progress into clinical trials.

\subsection{Phytocannabinoids in the treatment of CNS neurodegenerative diseases}

\subsubsection{Historical background}


Neurodegenerative disorders such as Alzheimer's disease (AD) and Parkinson's disease (PD) are characterised by a progressive loss of viable, functional neurons within one or more regions of the CNS, leading to specific deficits that increase in severity as the disorder progresses. A strong neuroinflammatory response is also observed in AD and PD (Lee et al., 2010; Qian et al., 2010) and is characterised by activation of microglia and the release of inflammatory agents. This inflammatory response is now itself considered a significant pathological cause of neurodegeneration. Additionally, the autoimmune CNS disease MS is also understood to have a neurodegenerative element crucial to the pathology of the disease which worsens in parallel with the development of symptoms (Stadelmann et al., 2011). Thus, although AD, PD and MS have distinct aetiologies, they all exhibit both neurodegeneration and inflammation. As described above, cannabis has been used for many thousands of years in the treatment of a wide range of disorders and illnesses; the first historical uses of cannabis in a wide range of neurological disorders are comprehensively discussed in Russo (2007). Neuroprotective effects of cannabis have been suggested as early as 1200 A.D. in India (Shou-Zhong, 1997) and more recently in the West when treating dementia (Reynolds, 1868). Prolonged use of an Indian hemp preparation was also reported to "quiet the tremor for a time" for a patient with Parkinson's in 1888 by Sir William Gowers (Gowers, 1888). More recently, a survey sent to PD sufferers treated at the Prague Movement Disorder Centre reported a benefit of cannabis in nearly half of respondents (Venderova et al., 2004). These reports, alloyed with the anti-inflammatory, antioxidant and immunomodulatory properties of several pCBs (Section 3.3) have led to preclinical research in animal models of neurodegenerative diseases and, in some cases, limited human trials in AD, HD and PD, which are outlined below.

Whilst a significant clinical benefit of pCBs for many neurodegenerative disorders has yet to fully manifest, the link between cannabis and the relief of MS symptoms, primarily spasticity, has a richer history. The first reference to the muscle relaxant properties of cannabis may have been as early as the $9^{\text {th }}$ century A.D. (Russo, 2007), with further reports by O'Shaughnessy in the $19^{\text {th }}$ century (O'Shaughnessy, 1840). Small-scale human studies into the beneficial effect of cannabis and $\Delta^{9}$-THC on MS symptoms between 1983 and 2002 (for review see Rog, 2010), as well as anecdotal reports of benefits and a report from the British Medical Association (1997), prompted the British government to call for a large-scale clinical 
investigation of the effects of cannabis on MS (House of Lords, 1998). Additionally, changes in the ECS, particularly $\mathrm{CB}_{1}$ receptor expression, have been shown to occur in human and experimental Parkinsonism (Silverdale et al., 2001; Hurley et al., 2003; Walsh et al., 2010) and Huntington's disease (HD) (Blazquez et al., 2011), suggesting $\mathrm{CB}_{1}$ receptors may be a target for drug interventions in these diseases. In the following section we discuss the extant, largely clinical, data regarding the effect of SCEs on MS symptoms and associated preclinical research. Following this, the preclinical research on pCB effects in animal models of AD, PD and HD is summarised, as are the limited number of relevant human studies.

\subsubsection{Phytocannabinoids in multiple sclerosis (MS)}

MS is a chronic, progressive disease that is most frequently diagnosed in young adults. The majority of patients experience acute attacks followed by months or even years of remission, with attacks becoming progressively more severe in later life (Compston \& Coles, 2008). The pathological basis of MS is the formation of inflammatory, demyelinating lesions in the CNS with resultant axonal loss, neuronal death and sclerotic plaques result (for review, see Stadelmann et al., 2011). Preclinical research from animal models of MS has suggested a potential role for $\mathrm{pCBs}$ in the attenuation of inflammation and the protection of neurons at risk of damage. As early as $1989, \Delta^{9}$-THC was reported to delay or prevent signs of symptom onset in the experimental allergic encephalomyelitis model of MS in mice, as well as increasing survival rates and decreasing neuroinflammation (Lyman et al., 1989). Recent work has indicated that $\mathrm{CB}_{1}$ and $\mathrm{CB}_{2}$ agonists, including $\Delta^{9}-\mathrm{THC}$, can limit symptoms, relapses, axonal loss and neuroinflammation in rodent models of MS (Arevalo-Martin et al., 2003; Croxford \& Miller, 2003; Docagne et al., 2007; Maresz et al., 2007; Hasseldam \& Johansen, 2010). $\Delta^{9}$-THC (10 $\mathrm{mg} / \mathrm{kg}$ ) has also been reported to control spasticity in the chronic relapsing experimental allergic encephalomyelitis mouse model of MS via a $\mathrm{CB}_{1}$-dependent mechanism (Baker et al., 2000).

Clinical investigation of SCEs in the treatment of MS symptoms have focussed on extracts with $\Delta^{9}$-THC and CBD as their primary active ingredients; other $\mathrm{pCB} / \mathrm{plant}$ matter is minimised at $<10 \%$. The reader is directed to two additional reviews by Lakhan \& Rowland (2009) and Rog (2010) for a more detailed description of these studies. The cannabinoids in MS study (CAMS) investigated the effects of dronabinol (Marinol, a synthetic $\Delta^{9}$-THC) and 
Cannador (2.5:1.25mg $\Delta^{9}$-THC:CBD SCE delivered in capsule). In a randomised, large-scale, placebo-controlled trial, neither dronabinol nor SCE (maximum $\Delta^{9}$-THC dose $25 \mathrm{mg} /$ day) significant affected objective (Ashworth Scale) measures of spasticity, but strong positive outcomes were observed for both drugs against control as assessed by patient-reported measures of spasticity and pain (Zajicek et al., 2003). A one-year follow up in which patients remained on their treatment suggested that the patient-reported benefit is maintained (Zajicek et al., 2005). The pattern of strong significant improvements in patient-reported measures of spasticity combined with changes in objective spasticity measures in favour of the SCE, but not significantly so, is common for SCE clinical studies; however, a significant improvement in Ashworth Scale scores was reported by Vaney et al. (2004) after treatment of 57 patients for two weeks with a $\Delta^{9}$-THC/CBD SCE (maximum dose $30.8 \mathrm{mg} / 10.8 \mathrm{mg} \Delta^{9}$-THC/CBD per day).

Sativex (2.7:2.5 mg/100 $\mu \mathrm{l}$ spray marketed as Nabiximols) is delivered as an oromucosal spray, the benefit of which is a faster plateau of plasma concentrations compared to the oral route (GW Pharmaceuticals, 2001). Sativex is now licenced in a number of countries for adjunctive treatment of spasticity in MS, as well as for neuropathic pain in Canada. Wade and co-workers measured the effect of Sativex ( $<120 \mathrm{mg} /$ day) on a variety of MS symptoms, and found that patient-reported (visual analogue scale) spasticity scores were significantly lowered by Sativex (Wade et al., 2004). A long-term open label extension found that Sativex maintained this beneficial effect (Wade et al., 2006). Collin et al. (2007) also reported significant improvements in spasticity as measured by a patient-reported daily numerical rating scale (NRS) score of spasticity, the primary endpoint. Secondary outcomes (including Ashworth Scale outcomes) were non-significantly in favour of Sativex (up to 48 doses/day Sativex). Most recently, a largescale trial used an initial four-week single-blind Sativex regimen to identify a patient population that responded well to Sativex (maximum 12 sprays/day; Novotna et al., 2011). Around $40 \%$ of patients had spasticity NRS results that were improved by $\geq 20 \%$ in the first four weeks; these responders were randomised into a double-blind, placebo-controlled study (12 weeks), and Sativex was shown to significantly improved spasticity NRS scores and several other secondary outcomes, including spasm frequency and sleep disturbances.

Sativex, CBD and dronabinol were each found to be effective in treating MS-related and neuropathic pain in a recent meta-analysis (Iskedjian et al., 2007). Additionally, one double- 
blind, randomised placebo-controlled five-week trial reported a significant effect of Sativex in alleviating MS-related pain (maximum 48 sprays/day; Rog et al., 2005). This effect was maintained without signs of tolerance in an open-label, uncontrolled two year extension that recruited participants from the previous trial (Rog et al., 2007). Further investigation into whether pCBs can alter the progression of MS in addition to effectively ameliorating symptoms could provide further justification for cannabis-based treatments for this disease, such investigations are currently in progress in the CUPID (Cannabinoid Use in Progressive Inflammatory Brain Disease) long-term (three year) study in which 493 MS patients are randomised to a placebo or $\Delta^{9}$-THC treatment group (Clinical Neurology Research Group, 2009).

\subsubsection{Phytocannabinoids in Alzheimer's disease (AD)}

$\mathrm{AD}$ is the most common form of dementia, with age being a significant risk factor. $\mathrm{AD}$ is associated with the formation of neurofibrillary tangles, senile plaques and cortical atrophy (Perl, 2010). At present, there is limited preclinical data regarding the effects of pCBs in animal models of AD. A single in vitro study has suggested that $\Delta^{9}$-THC competitively inhibits acetylcholinesterase (Eubanks et al., 2006), a therapeutic strategy that is approved to treat mild to moderate $\mathrm{AD}$ (Ellis, 2005). Iuvone and colleagues have shown that $\mathrm{CBD}(\geq 0.1 \mu \mathrm{M})$ decreases levels of $\beta$-amyloid-associated reactive oxygen species and lipid peroxidation in PC12 cells and in vivo (Iuvone et al., 2004). Extending these studies, Esposito et al. (2006) demonstrated that $\mathrm{CBD}(\geq 1 \mu \mathrm{M})$ attenuated a $\beta$-amyloid-induced increase in iNOS, also decreasing levels of $\mathrm{p} 38$ MAP kinase and NF- $\kappa \mathrm{B}$, both of which are involved in the response to oxidative stress. The same group showed that $\mathrm{CBD}(2.5$ and $10 \mathrm{mg} / \mathrm{kg})$ attenuated the $\beta$-amyloid inflammatory response in vivo by limiting iNOS and IL-1 $\beta$ expression (Esposito et al., 2007). More recently, Martin-Moreno et al. (2011) have shown that CBD $(20 \mathrm{mg} / \mathrm{kg})$ can limit microglial activation in in vitro and in vivo models of $\mathrm{AD}$.

In line with limited preclinical data available at present, there is no published data describing clinical effects of pCBs on human AD (Krishnan et al., 2009), with the exception of a single, small (six subject), open-label, non-placebo controlled study which reported that synthetic $\Delta^{9}$-THC (dronabinol; $2.5 \mathrm{mg} /$ day) alleviates night-time agitation in patients with $\mathrm{AD}$ or vascular 
dementia (Walther et al., 2006). Reports of CBD effects on in vitro and preclinical in vivo models of $\mathrm{AD}$, allied with the high tolerability of $\mathrm{CBD}$ in humans, suggest that further investigation of therapeutic potential is merited in $\mathrm{AD}$, particularly given that seizures are a common symptom of AD (Leppik \& Birnbaum, 2010) that could also benefit from the anticonvulsant effects of CBD described previously.

\subsubsection{Phytocannabinoids in Parkinson's disease (PD)}

PD is primarily a movement disorder characterised by bradykinesia, tremor at rest and rigidity. The death of nigral dopaminergic neurons that innervate the striatum and modulate motor behaviour is responsible for these motor symptoms, resulting in a loss of tyrosine hydroxylase positive (TH+) neurons in the substantia nigra and reduced dopamine levels in the striatum. Neuropsychiatric symptoms are also common, as are sleep disturbances (for review, see Hindle, 2010). The effects of CB receptor ligands and pCBs on neuronal death, motor symptoms and inflammation have been widely investigated in preclinical animal models of Parkinsonism and there is evidence that $\mathrm{pCBs}$ can provide symptomatic relief and neuroprotection from experimentally-induced Parkinsonism.

Evidence for the efficacy of $\Delta^{9}$-THC in ameliorating motor symptoms in PD models is mixed. Meschler et al. (2001) found that $\Delta^{9}$-THC (>1 mg/kg) exacerbated of Parkinson-like bradykinesia induced by administration of MPTP, a toxin that kills dopaminergic neurons, into the substantia nigra in cynomolgus monkeys. By contrast, $\Delta^{9}-\mathrm{THC}(\sim 4 \mathrm{mg} / \mathrm{kg})$ caused improvement in both activity and hand-eye coordination in MPTP-treated marmosets (van Vliet et al., 2008). The contrasting results could be explained by the use of different monkey species, MPTP- and $\Delta^{9}$-THC-dosing regimens, and clinical measures of Parkinsonism. In MPTP-treated marmosets, CB receptor agonism by the synthetic $\Delta^{9}$-THC analogue (nabilone, $\geq 0.1 \mathrm{mg} / \mathrm{kg}$ ) has been reported to decrease L-DOPA-induced dyskinesias (Fox et al., 2002). Rats that received daily treatment with $\Delta^{9}$-THC or CBD (both $3 \mathrm{mg} / \mathrm{kg}$ ) for 2 weeks post-lesion had significantly higher levels of TH mRNA and dopamine ipsilateral to the lesion compared to vehicle-treated animals in the 6-hydroxydopamine (6-OHDA) model of PD (Lastres-Becker et al., 2005). This neuroprotective effect is likely to be $\mathrm{CB}_{1}$-independent, due instead to the antioxidant capacity of pCBs (Garcia-Arencibia et al., 2007). 
$\Delta^{9}$-THCV has an attractive range of properties in relation to PD, $\Delta^{9}$-THCV is likely to share the neuroprotective antioxidant properties possessed by other pCBs and can act as a $\mathrm{CB}_{2}$ agonist in vivo (Bolognini et al., 2010; Pertwee, 2008), and can therefore affect microglial activation; additionally, $\Delta^{9}-\mathrm{THCV}$ is a $\mathrm{CB}_{1}$ antagonist, and the $\mathrm{CB}_{1}$ antagonist SR141716A (0.1 $\mathrm{mg} / \mathrm{kg}$ ) has been shown to ameliorate motor symptoms in animal models of Parkinsonism (Gonzalez et al., 2006; Garcia-Arencibia et al., 2008; Kelsey et al., 2009). Acute administration of $\Delta^{9}$-THCV ( $2 \mathrm{mg} / \mathrm{kg}$ ) has recently been shown to improve motor performance in the 6-OHDA model of Parkinsonism in rat (Garcia et al., 2011); $\Delta^{9}$-THCV increased striatal glutamate, but not dopamine, levels in a manner consistent with $\mathrm{CB}_{1}$ antagonism. In the same study, chronic $\Delta^{9}$ THCV $(2 \mathrm{mg} / \mathrm{kg})$ administration partially protected $\mathrm{TH}+$ cells from 6-OHDA-induced death, attenuated microglial activation and also exerted a significant neuroprotective effect on nigral $\mathrm{TH}+$ neurons in the LPS model of PD in mice. The LPS model exhibits greater $\mathrm{CB}_{2}$ upregulation than the 6-OHDA model; the effectiveness of a $\mathrm{CB}_{2}$-specific agonist and the exacerbation Parkinsonism in mice lacking $\mathrm{CB}_{2}$ receptors suggest $\Delta^{9}-\mathrm{THCV}$ may be neuroprotective in a $\mathrm{CB}_{2}$-dependent manner in this model (Garcia et al., 2011).

Investigation of the effects of cannabis and pCBs in human PD is limited. Small-scale human studies have investigated the effect of nabilone (Sieradzan et al., 2001) and Cannador (Carroll et al., 2004) on dyskinesias caused by the most common PD treatment, L-DOPA. Whilst nabilone $(0.03 \mathrm{mg} / \mathrm{kg})$ was reported to significantly improve dyskinesias in pilot trial in 7 patients as assessed by the Rush Dyskinesia Scale (Sieradzan et al., 2001), two patients withdrew due to adverse side-effects. Cannador (maximum $\Delta^{9}$-THC dose of $0.17 \mathrm{mg} / \mathrm{kg} / \mathrm{day}$ ) had no effect on dyskinesia as assessed by several parameters, although it was well-tolerated, possibly due to an earlier dose escalation study to determine suitable dosages (Carroll et al., 2004). CBD alone $(\leq 400 \mathrm{mg} /$ day) has been reported as effective in the treatment of PD-associated psychosis over four weeks of treatment in six consecutive patients presenting with three or more months history of psychosis (Zuardi et al., 2009), consistent with findings that CBD is an anti-psychotic (Zuardi et al., 2006). However, a study primarily concerned with dystonia found that CBD (>300 $\mathrm{mg} /$ day) aggravated Parkinsonism in two patients (Consroe et al., 1986). The Venderova et al. (2004) survey referred to previously represents the most promising finding regarding PD and human use of cannabis. A quarter of respondents reported cannabis (predominantly oral, not 
smoked) use for PD symptom relief. Nearly half (45.9\%) described a mild or substantial alleviation of symptoms above that provided by their prescribed treatment. Of these individuals, significant numbers reported improvements in resting tremor $(30.6 \%)$ and bradykinesia $(44.7 \%)$, $14.1 \%$ also reported alleviation of L-dopa-induced dyskinesia. $4.7 \%$ reported a worsening in symptoms (Venderova et al., 2004). This study, whilst a simple survey, indicates that further work is merited.

The use of pCBs in the treatment of various facets of preclinical experimentally-induced Parkinsonism appears promising. Specifically, although at an early stage of investigation, the combined properties of $\Delta^{9}-\mathrm{THCV}$ (antioxidant, $\mathrm{CB}_{1}$ receptor antagonist, $\mathrm{CB}_{2}$ receptor agonist) hold promise in combating neurodegenerative, immunological and motor function symptoms of PD; the anti-inflammatory and antioxidant properties of CBD are also attractive. The current clinical evidence is very limited in scope, and therefore whilst findings are not uniformly positive, more extensive human studies are required to ascertain whether preclinical promise can be translated into treatments for this age-dependent, poorly-controlled disorder.

\subsubsection{Phytocannabinoids in Huntington's disease (HD)}

HD is a movement disorder that also causes cognitive and behavioural changes (for review, see Kumar et al., 2010). An autosomal dominant mutation of the Huntingtin protein is responsible for HD, causing neuronal death in the striatum and other areas of the brain, with spiny GABAergic neurons most affected (Gil \& Rego, 2008). HD is also associated with a loss of $\mathrm{CB}_{1}$ receptors (Blazquez et al., 2011). CBD and $\Delta^{9}$-THC (both $5 \mathrm{mg} / \mathrm{kg}$ ) were neuroprotective in the 3-nitropropionic acid-induced striatal lesion HD model (Lastres-Becker et al., 2004; Sagredo et al., 2007); the effects of $\Delta^{9}$-THC were most likely mediated by $\mathrm{CB}_{1}$ receptors, whilst the effects of $\mathrm{CBD}$ were proposed to be due to antioxidant properties. However, daily treatment with $\Delta^{9}$ THC (10 mg/kg over 8 weeks) reportedly had no effect on motor deterioration in a mouse transgenic model of HD (Dowie et al., 2010).

A small clinical trial following daily CBD (300-600 mg) treatment demonstrated an improvement in HD symptoms in 1 of 4 participants (Sandyk et al., 1989); however, a doubleblind randomised placebo-controlled crossover trial in 15 HD patients showed no significant effect of CBD (10 mg/kg/day, 6 weeks) on chorea severity (Consroe et al., 1991). More recently, 
a randomised, double-blind crossover placebo-controlled trial with 37 patients investigating the effects of the synthetic $\Delta^{9}$-THC analogue nabilone (1-2 mg) showed no effect on the primary outcome (the Unified Huntington's Disease Rating Scale), but some evidence of improvement in chorea and neuropsychiatric outcomes (Curtis et al., 2009). As with other disorders, further clinical research is required into the effects of $\mathrm{pCBs}$ in $\mathrm{HD}$ to elucidate the potential benefits. The recent finding that loss of striatal $\mathrm{CB}_{1}$ receptor expression may be an important factor in the pathogenesis of HD (Blazquez et al., 2011) indicates that the ECS system is a rational target for HD treatment, which may include pCB-based medicines.

\subsubsection{Summary}

The ability of a combination of $\Delta^{9}$-THC and CBD to decrease symptoms associated with MS has led to the introduction of Sativex, the first licensed pCB drug. Moreover, there is increasing preclinical evidence that indicates pCBs may also be of benefit in treating the development of several neurodegenerative disorders; in particular, CBD's ability to modulate immune cell activity in the CNS and limit oxidative stress is promising and confers strong neuroprotective capacity. However, it should be noted that previously proposed, putative treatments for neurodegenerative diseases that exploit antioxidant and anti-inflammatory strategies have, in many cases, met with limited clinical success (Dumont \& Beal, 2011; Whitton, 2010). Apart from the positive data gathered in the past decade on the effects of SCEs on MS symptoms, at present there is very little human data available on pCB effects in neurogdegenerative disorders. Thus, coordinated clinical trials investigating the effect of pCBs on both disease progression and symptom control for a range of neurodegenerative disorders are required to determine if and how pCBs can benefit patients with AD, HD and PD, all of which have a significant unmet clinical need. Encouragingly, most pCB-based treatments investigated to date, independent of the target disorder, appear to be well-tolerated, a promising sign for further clinical studies. Whilst most research has been performed on $\mathrm{CBD}$, other $\mathrm{pCBs}$ share antioxidant capacity and may be more suited to specific diseases states. For example, $\Delta^{9}$-THCV effects in models of PD appear to limit both neuronal cell death and the associated immune response whilst decreasing signs of bradykinesia. 


\subsection{Phytocannabinoids in affective disorders}

In this section, we consider affective disorders; it is notable that $\mathrm{pCBs}$ also have effects in nonaffective psychosis disorders, including schizophrenia (Hallak et al., 2011), however, such actions are not considered here.

\subsubsection{Historical background}

Cannabis has been used as a treatment for mood disorders for several thousand years, with welldocumented use as a hypnotic and tranquilizer in the treatment of anxiety, mania, and hysteria (Mechoulam et al., 1970). Use of the plant continued into the early part of the $20^{\text {th }}$ Century, where extracts have been used for their sedative and hypnotic properties to treat insomnia, melancholy, mania, and delirium (Russo \& Guy, 2006). However, a decline and eventual cessation of cannabis use in psychiatry occurred over the last 100 years due to the development of new and more selective hypnotic and sedative drugs with well-characterised modes of action, alongside prohibition of use of the plant. However, the recent isolation and identification of pCBs with little or no psychoactivity is of particular relevance here and gives rise to the prospect of new therapeutic agents which may be used for the treatment of the affective disorders.

\subsubsection{Phytocannabinoids in anxiety}

Cannabis use has been associated with a high prevalence of anxiety; however, individual pCBs have been shown to possess anxiolytic properties (Crippa et al., 2009; Crippa et al., 2011) and thus use of specific pCBs (or selected combinations thereof) may hold as yet unexploited, therapeutic potential in the treatment of anxiety disorders.

There is evidence to suggest a significant comorbidity between cannabis use and prevalence of anxiety disorders. Reilly et al. (1998), using a structured interview in a rural area of Australia, found that $21 \%$ of long-term cannabis users reported high levels of anxiety, paranoia or depression. Similarly, Saban et al. (2010) investigating the relationship between substance misuse and psychopathology in high school students, reported a significant association between cannabis use and levels of anxiety. Furthermore, a recent study in Italian university students demonstrated a link between cannabis use and levels of anxiety which may, in turn, trigger risky and suicidal behaviour (Innamorati et al., 2008). In a study with 18-year-old New 
Zealanders, it was reported that those who had smoked cannabis at least ten times between the ages of 15 and 16 had twice the prevalence of anxiety disorders compared to those who had never used the drug (Fergusson \& Horwood, 1997). Likewise, in a study investigating emotion regulation and mental health problems, Dorard et al. (2008) found that more than half of the cannabis abusers reported comorbid diagnosis of CNS disorders, most commonly affecting mood and anxiety.

By contrast, it has been suggested that subjects with high levels of anxiety and patients with anxiety disorders use cannabis as a form of "self-medication" to treat symptoms. In support, an elegant analysis of the US National Comorbidity Survey showed that a large proportion of subjects developed anxiety disorders prior to the onset of their first symptoms of cannabis dependence, implying that the subjects were self-administering cannabis as an anxiolytic medication (Agosti et al., 2002). In line with this hypothesis, Buckner \& Schmidt (2008) examined the temporal sequencing between the onset of seasonal affective disorder (SAD), alcohol misuse and cannabis dependence. Using a sample of participants from the Oregon Adolescent Depression Project, it was reported that SAD was an independent risk factor for the subsequent onset of cannabis dependence (Buckner \& Schmidt, 2008). Overall, whilst cannabis may be anxiogenic in otherwise healthy cohorts, there are clear indications of anxiolytic effects in sufferers of anxiety disorders

The anxiolytic effects of CBD have been thoroughly investigated in preclinical models. The earliest reported study by Zuardi \& Karniol (1983) showed that purified CBD (10 mg/kg) significantly decreased conditioned emotional responses to a stimulus in rats. Resstel \& colleagues used a restraint stress paradigm in rats, which raises blood pressure and increases heart rate indicative of human anxiety behaviour, to demonstrate that CBD (1- $20 \mathrm{mg} / \mathrm{kg})$ decreased acute autonomic responses (Resstel et al., 2009). Similarly, Guimaraes et al. (1990) showed that mice treated with 2.5-10 mg/kg (but not $20.0 \mathrm{mg} / \mathrm{kg}$ ) CBD spent a greater amount of time in the open arm of an elevated plus maze, an effect similar to that produced by the standard anxiolytic agent diazepam. The anxiolytic actions of CBD have also been demonstrated in the mouse model of social defeat (Pistovcakova et al., 2006), the Vogel conflict test (Moreira et al., 2006), the conditioned fear paradigm (Resstel et al., 2006) and the contextual fear memory 
extinction paradigm (Bitencourt et al., 2008). Taken together, the results from animal studies suggest that CBD has anxiolytic potential.

Preclinical data have led to a number of studies investigating possible anxiolytic actions in healthy and clinical human populations. An early study using healthy volunteers subjected to a stressful public-speaking test (SPST) showed that CBD (300 mg) reduced the volunteer's subjective anxiety to levels comparable with the standard anxiolytic, diazepam (Zuardi et al., 1993). A follow-up study by the same group (Crippa et al., 2004) used functional neuroimaging to demonstrate that CBD (400 mg) significantly decreased subjective anxiety; importantly, CBD also significant decreased regional cerebral blood flow ( $\mathrm{rCBF}$ ) in the left hippocampal and parahippocampal gyrus regions, indicative of an action on limbic and paralimbic brain areas. Later, Fusar-Poli et al. (2009) used functional magnetic resonance imaging to investigate neural correlates of the anxiolytic properties of CBD, demonstrating that CBD $(600 \mathrm{mg})$ reduced amygdala, anterior cingulate cortical and posterior cingulate cortical activity in 15 healthy subjects subjected to a sequence of fearful facial stimuli. A recent study substantiated the role of CBD, whereby increases in anxiety induced by the SPST on subjects with SAD was reduced by CBD (600 mg) (Bergamaschi et al., 2011). In a clinical context, Crippa et al. (2011) investigated the effects of CBD treatment in 10 patients with generalised SAD; CBD (400 mg) significantly reduced subjective anxiety and led to reduced $\mathrm{rCBF}$ in left parahippocampal gyrus, hippocampus and inferior temporal gyrus, while increasing $\mathrm{rCBF}$ in right posterior cingulated gyrus. The authors suggest that CBD produces its anxiolytic actions due its effects on activity in limbic and paralimbic brain areas. To date, no studies have investigated the actions of other pCBs on anxiety, but it seems that CBD has promise as an anxiolytic agent. The description of both anxiogenic and anxiolytic actions of ingested cannabis also raise the possibility that individual pCBs have differential effects on anxiety; for example, anxiolytic CBD may oppose the anxiogenic effects of $\Delta^{9}$-THC (Zuardi et al., 1982); such a description would fit well with the general concept that $\mathrm{CBD}$ can usefully ameliorate unwanted $\Delta^{9}$-THC effects discussed previously.

\subsubsection{Phytocannabinoids in depression}


Elevation in mood and reduction in levels of stress following recreational cannabis use have been documented anecdotally for many years (Skolnick et al., 2001). Indeed, a recent internet survey comparing individuals with differing levels of marijuana use showed that those who used marijuana daily and those who used marijuana once per week or less reported less depressed mood and more positive affect than non-users (Denson \& Earleywine, 2006). However, a review of the literature also reveals that cannabis ingestion is associated with an increased incidence of bipolar disorders and depression (Jarvis et al., 2008; van Rossum et al., 2009). As a result of these bi-directional effects research has largely focussed on understanding the role of the ECS in the pathogenesis and treatment of depression, rather than an investigation of the potential therapeutic actions of pCBs (for a recent review see Parolaro et al., 2010). Here, we will restrict our discussion to studies that have investigated the actions of individual pCBs in depressive syndromes.

The suggestion of a potential antidepressant role for $\Delta^{9}$-THC is widespread. In the early 1980's the effects of $\Delta^{9}$-THC (2.5 and $10 \mathrm{mg} / \mathrm{kg}$ delivered by paced smoking of herbal cigarettes) showed increases in relaxation and decreases in subjective ratings of anxiety, tension and depression (Ashton et al., 1981). In a clinical setting, significant antidepressant actions of $\Delta^{9}$-THC treatment have been documented in patients suffering advanced cancer (Regelson et al., 1976), MS (Martyn et al., 1995; Svendsen et al., 2004) or chronic pain (Notcutt et al., 1997; Wade et al., 2003). However, as suggested above, evidence in support of a cannabis antidepressant action is equivocal. An early study by Kotin et al. (1973) reported that in 8 hospitalized patients with moderate to severe depression, $\Delta^{9}$-THC administered for up to 7 days failed to exhibit any significant antidepressant response; however, the small sample size, limited study duration and relative severity of symptoms may hinder a firm conclusion from this study.

A comprehensive analysis of the potential antidepressant action of isolated pCBs has recently been reported by El-Alfy et al. (2010), where antidepressant actions of major pCBs were evaluated in the forced swim test (FST) model in mouse. Compounds that showed an antidepressant action in the FST were additionally tested in the tail suspension test (TST). Both the FST and TST are standard preclinical tests used to measure the effect of antidepressant drugs. Classically, the results of these tests have been interpreted such that the time spent immobile is considered a behavioural correlate of negative mood. Treatment with $2.5 \mathrm{mg} / \mathrm{kg} \Delta^{9}$-THC (but not 
1.25 or $5.0 \mathrm{mg} / \mathrm{kg}$ ) produced a significant reduction in overall immobility time in both the FST and TST, consistent with an antidepressant action. Interestingly, similar reductions in time spent immobile in both the FST and TST were also seen with CBC. Here, $20 \mathrm{mg} / \mathrm{kg}$ CBC elicited decreased immobility time in the FST, whilst both 40 and $80 \mathrm{mg} / \mathrm{kg} \mathrm{CBC}$ were effective in the TST. Finally, $200 \mathrm{mg} / \mathrm{kg}$ CBD decreased time spent immobile in the FST, but failed to show any further anti-depressant actions in the TST; treatment with $\Delta^{8}$-THC, CBG or CBN failed to elicit any antidepressant-like actions (El-Alfy et al., 2010). Only one other study has investigated the actions of CBG to alleviate depression, CBG $(40-80 \mathrm{mg} / \mathrm{kg}$ ) produced significant reductions in the time spent immobile in the TST, with comparable effects to a known anti-depressant dose of imipramine (Musty \& Deyo, 2006). Work by the same authors has also demonstrated a potential anti-depressant role for CBC (greatest activity seen at $40 \mathrm{mg} / \mathrm{kg}$ ) using the TST (Deyo \& Musty, 2003).

Of the non- $-\Delta^{9}$-THC pCBs, CBD appears to be the most thoroughly researched for its antidepressant actions. However, as highlighted by El-Alfy et al. (2010), results to-date have not always been consistent. Following the successful demonstration that CBD administration could reduce the behavioural consequences of restraint stress (Resstel et al., 2009), it was further shown that CBD (30, but not 3,10 or $100 \mathrm{mg} / \mathrm{kg}$ doses) increased time spent swimming in the FST (Zanelati et al., 2010); interestingly, pre-treatment with a 5- $\mathrm{HT}_{1 \mathrm{~A}}$ receptor antagonist blocked CBD action. Finally, in a small-scale human trial, 2 patients suffering bipolar affective disorder and experiencing a manic episode failed to show any improvement in symptoms in response to CBD treatment for 25 days (initial oral dose of $600 \mathrm{mg} /$ day rising to $1200 \mathrm{mg} / \mathrm{day}$ ), although this may reflect a differing aetiology underlying positive and negative symptoms in bipolar disorder (Zuardi et al., 2010).

\subsubsection{Summary}

These data suggest that, in the future, individual $\mathrm{pCBs}$ may have important therapeutic advantages over the ingested cannabis used in earlier studies in the treatment of affective disorders. At present, $\mathrm{CBD}$ is the most likely $\mathrm{pCB}$ to be translated into clinical practice due to its non-psychoactivity, safety and tolerability. However, long-term, double-blind, placebo- 
controlled trials with subjects suffering from different affective disorders are still necessary and critical for this to be realised.

\subsection{Phytocannabinoids and feeding-related disorders}

In this section, we will explore the actions of the pCBs on food intake, a phenomenon that is intimately associated with modulation of feeding circuits in the hypothalamus by the eCB system, at present proposed to be principally due to an action on $\mathrm{CB}_{1}$ receptors (Pagotto et al., 2006; Di Marzo et al., 2009). Whilst a detailed description of brain reward circuitry and interactions with the eCB system is beyond the scope of this article, several authors have reviewed these aspects in detail (Cota et al., 2003; Kirkham, 2008). It is clear that food intake may activate eCBs to stimulate reward pathways to engender further feeding behaviour. $\mathrm{CB}_{1}$ receptor antagonists are well-known anti-obesity agents (Lee et al., 2009); however, obesity per se is not a solely CNS disease, rather, our discussion will be related to clinical conditions such as cachexia, anorexia and malnutrition, including the establishment of such conditions as a consequence of diseases such as AIDS, cancer and AD, diseases in which a disorder of appetite is a core feature.

\subsubsection{Historical background}

The appetite-stimulating, orexigenic properties of marijuana have been documented as far back as 300 A.D. (Chopra \& Chopra, 1939). However, this seemingly well-substantiated phenomenon was previously only sparsely supported by empirical evidence, with few detailed human studies and even fewer well-controlled animal studies. In an early report, Hollister (1971) demonstrated that a single oral dose of marijuana (containing $0.35 \mathrm{mg} / \mathrm{kg} \Delta^{9}$-THC) significantly increased intake of milkshakes in normal, unfasted volunteers. Foltin and colleagues showed that volunteer subjects given marijuana cigarettes $\left(1.84 \% \mathrm{w} / \mathrm{w} \Delta^{9}\right.$-THC) showed a markedly increase in food intake (1500 kcal), primarily attributable to an increase in snack food items (Foltin et al, 1986; Foltin et al., 1988).

In animals, the first comprehensive dose-response analysis of $\Delta^{9}$-THC hyperphagia in rats was documented in the late 1990s (Williams et al., 1998); a range of $\Delta^{9}$-THC doses were administered orally to pre-satiated rats with significant hyperphagia seen at doses $\geq 0.5 \mathrm{mg} / \mathrm{kg} \Delta^{9}$ THC. Subsequently, this hyperphagia was shown to be mediated by $\mathrm{CB}_{1}$ receptors (Williams \& 
Kirkham, 2002b), and involved a marked reduction in latency to begin feeding (Williams \& Kirkham, 2002a). Together these effects imply that the stimulation of feeding induced by $\Delta^{9}$ THC may be linked to the appetitive phase of feeding, being associated with orienting an animal toward food and increasing the salience or reward value of food stimuli. The concept of cannabinoids influencing reward processes is well-established and has been supported by findings that blockade of $\mathrm{CB}_{1}$ receptors by SR141716A reduced sensitivity to the rewarding effects of electrical brain stimulation (Arnold et al., 2001; Deroche-Gamonet et al., 2001) and blocked the acquisition of drug- or food induced place preferences (Chaperon et al., 1998). Conversely, stimulation of $\mathrm{CB}_{1}$ receptors underlie the motivation to obtain and ingest palatable ingesta (Gallate \& McGregor, 1999; Gallate et al., 1999; Higgs et al., 2003). Overall, current evidence suggests that animals work harder to obtain food after $\Delta^{9}$-THC treatment, and eat earlier and more frequently when food is freely available.

At present, clinical interventions involving $\mathrm{pCBs}$ in syndromes affecting food consumption are dominated by use of $\Delta^{9}$-THC and synthetic analogues. Cachexia is characterised by metabolic changes associated with a severe loss of appetite (McGrath, 2002) and is a common feature of the later stages of diseases such as AIDS and metastatic cancer (Cat \& Coleman, 1994; Inui, 2002). Thus, treatments aimed at stimulating appetite by enhancing the attractiveness and enjoyment of food should be beneficial in these circumstances. Sacks and colleagues found that treatment with dronabinol ( $5 \mathrm{mg}$, three times daily) had little effect on food intake, but greatly attenuated the reduction in daily energy intake produced by chemotherapy (Sacks et al., 1990). In the field of HIV-wasting syndrome, chronic daily dronabinol treatment (5-20 mg, orally for up to 20 weeks), caused a highly significant increase in appetite and mood ratings, with the majority of patients gaining weight over the course of treatment (Plasse et al., 1991). Similarly, Beal et al. (1995) evaluated the long-term effects of $\Delta^{9}$-THC or placebo in patients with AIDS-related appetite and weight loss; dronabinol (2.5 mg, twice per day over 42 days) administered to patients who had suffered progressive weight loss, experienced either stabilization of their body or a modest weight gain, accompanied by substantial increases in appetite.

Wasting and loss of appetite are also important features of ageing and associated conditions such as dementia (Morris \& Volicer, 2001; Hickson, 2006). It is therefore possible 
that the appetite-stimulating properties of cannabinoids may be a useful tool in attempting to maintain proper nutrition in these populations. Dronabinol (5 $\mathrm{mg}$ per day over 6 weeks) produced significant weight gain, but not increases in energy intake, in food-refusing dementia patients (Volicer, 1997). Finally, a possible target for the application of cannabinoids to stimulate appetite and overcome food refusal may be in the treatment of anorexia nervosa, a psychiatric condition exemplified by self-starvation. Dronabinol has been used to successfully manage appetite in elderly patients suffering from anorexia and significant weight loss (Wilson et al., 2007). By contrast, a study in 11 female patients with primary anorexia nervosa failed to show an effect of $\Delta^{9}$-THC on daily changes in weight and caloric intake versus an active diazepam placebo (Gross et al., 1983). However, it should be noted that the underlying psychopathology of anorexia is very complex, and involves significant psychological factors that are unrelated to any dysfunction in the normal physiological mechanisms controlling eating.

\subsubsection{Phytocannabinoid standardised cannabis extracts (SCEs) in feeding-related disorders}

Despite the evidence of $\Delta^{9}$-THC stimulatory effect on feeding and appetite detailed above, relatively few studies have investigated the contribution of non- $\Delta^{9}-\mathrm{THC} \mathrm{pCBs}$ to the feeding effects of cannabis. However, recent work has demonstrated that a range of pCBs may have significant effects on feeding patterns (reviewed in Farrimond et al., 2011). In an initial study, the effects of purified $\Delta^{9}$-THC, synthetic $\Delta^{9}$-THC and $\Delta^{9}$-THC SCEs (which also contain an array of non- $\Delta^{9}$-THC pCBs) were compared (Farrimond et al., 2010a). Importantly, all treatments were matched to a range of $\Delta^{9}$-THC doses known to induce hyperphagia. Using standardised pre-feed paradigm (Williams et al., 1998), $\Delta^{9}$-THC SCE showed significantly lower hyperphagia in comparison to the synthetic and purified $\Delta^{9}$-THC doses; these data suggested that the combination of pCBs (and, potentially, non-pCB components) in the SCE attenuated the hyperphagic effects of $\Delta^{9}$-THC. In a follow-up study (Farrimond et al, 2010b), SCEs containing concentrations of $\Delta^{9}$-THC between two- and ten-fold lower than those previously demonstrated to induce hyperphagia, caused pre-satiated rats to significantly increase chow intake by reducing their latency to the first contact with food. These effects on feeding replicated those previously seen with much higher concentrations of pure $\Delta^{9}$-THC (Williams et al., 1998; Farrimond et al., 2010a) and indicate that cannabis compounds other than $\Delta^{9}$-THC may also have the ability to 
stimulate appetite, effects that were concealed when a higher concentration of $\Delta^{9}$-THC was present in the extract. It is clear from the data presented above (Farrimond et al., 2010a; Farrimond et al., 2010b) that the precise composition of an SCE is critical in determining the action on feeding, and that individual pCBs may antagonise the appetite-stimulating actions of $\Delta^{9}$-THC, whilst others may have appetite-stimulating properties themselves. Finally here, the action of two SCEs, one of these containing $67 \% \Delta^{9}$-THC, the other a $\Delta^{9}$-THC-free SCE have been investigated; all remaining pCBs in the SCE were kept constant (CBD: 0.3\%; CBG: 1.7\%; CBC: $1.6 \% ; \Delta^{9}$-THCV: $0.9 \%$; THCA: $0.3 \%$; CBN: $1.5 \%$; and sesame oil vehicle; total mixture dose range: $0.5-4.0 \mathrm{mg} / \mathrm{kg}$ ) (personal communication, J Farrimond). Administration of both $\Delta^{9}$ THC-free and 67\%- $\Delta^{9}$-THC SCEs induced highly significant dose-dependent increases in food consumption in the first hour after food was returned to the animals. This effect was attributed to highly significant reductions in the latency to the onset of feeding produced by both SCEs. However, some differences between the extracts were evident when considering other meal pattern parameters; most significantly, the $67 \% \Delta^{9}$-THC SCE significantly increase the duration of the first meal, whilst the $\Delta^{9}$-THC-free SCE failed to induce any significant effect. This finding echoes those of previous studies (Farrimond et al., 2010b), further implicating non- $\Delta^{9}$-THC $\mathrm{pCBs}$ in the appetitive actions of feeding only.

Despite these promising findings, only one single clinical trial has been undertaken to investigate the effects of an SCE on appetite and feeding. Strasser et al. (2006) compared the effects of Cannador (2.5 mg THC and $1 \mathrm{mg} \mathrm{CBD}), \Delta^{9}$-THC (2.5 mg) and placebo on appetite and quality of life in patients with cancer-related anorexia-cachexia syndrome (CACS). Here, adult patients suffering significant weight loss were treated twice daily for 6 weeks with measures of appetite, mood, and nausea monitored daily. Results showed no significant differences between the three treatments, with increased appetite ratings of $73 \%, 58 \%$, and $69 \%$ for patients receiving Cannador, THC, or placebo, respectively.

\subsubsection{Individual phytocannabinoids in feeding-related disorders}

Animal data presented to date strongly indicate that the non- $\Delta^{9}$-THC pCBs present in the SCEs produce significantly effects on the appetitive, but not consummatory, aspects of feeding behavior. Thus, determination of the effects of individual pCBs are clearly warranted; however, 
prior to 2009 there were few studies investigating the actions of individual non- $\Delta^{9}$-THC pCB on feeding, with the majority of these studies being either unreplicated or even contradictory. In all cases, no detailed analyses of changes to feeding microstructure had been undertaken, which necessarily limits the interpretation of these findings. In 1976, Sofia and Knobloch examined the acute effects of $\mathrm{CBN}$ and $\mathrm{CBD}$ (both $50 \mathrm{mg} / \mathrm{kg}$ ) on food and sucrose consumption. In this paradigm, animals were pre-trained to consume their total daily food intake during a 6 hour feeding period; water, $5 \%$ sucrose or $20 \%$ sucrose solutions were also available during this period. Both CBN and CBD significantly reduced food intake, effects which persisted for 4-5 days post-drug administration (Sofia \& Knobloch, 1976). CBN and CBD produced similar reductions in sucrose intake, which returned to pre-baseline levels by day 3-4 post-drug administration. The authors interpreted these findings as suggestive that CBN and CBD produced a preference for sweet calories. It should also be noted that the Sofia \& Knobloch (1976) study used doses of CBN and CBD between 200 and 1500 times greater than the concentrations of these compounds used in other studies that have suggested that non- $\Delta^{9}$-THC pCB stimulate feeding (Farrimond et al., 2010a; Farrimond et al., 2010b). Wiley et al. (2005) showed that CBD $(3-100 \mathrm{mg} / \mathrm{kg})$ failed to significantly alter food intake in mice; yet it should be noted that doses of 3 and $10 \mathrm{mg} / \mathrm{kg}$ CBD showed a non-significant trend towards an increase in intake suggesting that CBD may be worthy of further investigation. However, a recent study by Scopinho et al. (2011) further demonstrated that CBD (1, 10 or $20 \mathrm{mg} / \mathrm{kg}$ ) failed to alter feeding and failed to replicate the non-significant trend towards an increase in feeding at low doses. CBD ( 2.5 and $5 \mathrm{mg} / \mathrm{kg} /$ day for 14 days) has been reported to produce significant decreases in body weight in rats, although no measures of food intake were taken (Ignatowska-Jankowska et al. 2011); interestingly, $\mathrm{CBD}$ action was sensitive to co-administration of the $\mathrm{CB}_{2}$ receptor selective antagonist, AM630, suggesting a $\mathrm{CB}_{2}$ receptor mechanism may be critical to the action of $\mathrm{CBD}$ on body weight.

In general, there is a broad literature implicating $\mathrm{CB}_{1}$ receptor antagonists as potential anti-obesity agents; however, the recent failure of rimonabant has highlighted the need to develop safer alternatives (Lee et al., 2009; Izzo et al., 2009). In this regard, Riedel et al. (2009) have investigated the feeding effects of $\Delta^{9}-\mathrm{THCV}(3,10$ and $30 \mathrm{mg} / \mathrm{kg})$ and a $\Delta^{9}-\mathrm{THCV}$ SCE (containing between 0.1 and $0.3 \mathrm{mg} / \mathrm{kg} \Delta^{9}-\mathrm{THCV}$ ). All doses of $\Delta^{9}$-THCV significantly reduced 
food intake during the $12 \mathrm{~h}$ following treatment, whereas $\Delta^{9}$-THCV SCEs did not affect consumption. This study confirms that purified $\Delta^{9}-\mathrm{THCV}$ can reduce food intake in mice, which is worthy of further investigation. In particular, future work should investigate effects of purified $\Delta^{9}$-THCV and $\Delta^{9}$-THCV SCE using conditions which would be expected to maximise food intake (e.g. during the dark phase of the light:dark cycle or following periods of deprivation), thus ensuring high baseline food intake, maximizing the ability to detect any $\Delta^{9}$-THCV-induced decreases in food intake.

\subsubsection{Summary}

The association between the effects of exogenous CBs and appetite gave a strong lead in suggesting possible physiological roles for the ECS in feeding-related diseases. Indeed, $\Delta^{9}$-THC induces a degree of over-eating that far exceeds that produced by most other hyperphagic pharmacological manipulations. Crucially, the behavioural adjustments induced by exogenous CBs suggest that these compounds are involved in the processes which drive us to eat. Animals work harder to obtain food after $\mathrm{CB}_{1}$ stimulation, and eat earlier and more frequently when food is freely available. $\mathrm{CB}_{1}$ receptor agonists thus seem to actively provoke feeding, rather than merely prolonging eating that has been initiated through other mechanisms. More recent data has additionally shown a role for some non- $\Delta^{9}$-THC pCBs in the stimulation of appetite, however, no studies have clearly delineated the individual $\mathrm{pCB}$ which may underlie these appetite-stimulating actions. Thus, further studies in animal models and humans are needed to confirm the ability of individual $\mathrm{pCBs}$ to alter food intake, and to clarify the mechanisms of action underlying these effects, such initiatives may lead to the development of novel therapeutic strategies for the treatment not only of feeding disorders themselves, but also disorders arising as a symptom of other CNS diseases.

\section{Conclusions}

The demonstration that Cannabis sativa contains numerous $\mathrm{pCBs}$ in addition to the major psychoactive $\Delta^{9}$-THC component provides the impetus to support a solid body of preclinical studies focussing on therapeutic development of non- $\Delta^{9}$-THC pCBs. Work in animal models of diseases is now being extended to an increasing number of clinical trials in human CNS 
disease. The latter, in particular, has been fuelled by the introduction of the first SCE- and, by extension, pCB-, based medicine, Sativex. As well as providing a useful proof-of-concept, the introduction of Sativex may serve to lower the barriers to the perceived societal difficulties associated with cannabis-based medicines. In general, where $\Delta^{9}$-THC has been shown to be an effective treatment in animal models or clinically, the adverse side effects of $\mathrm{CB}_{1}$ agonism need to be weighed against the clinical benefit to patients; however, the combination of $\Delta^{9}$-THC and CBD into an SCE yields a medicine that is well-tolerated in the clinic, suggesting that the presence of $\Delta^{9}$-THC does not necessarily preclude the development of medicines suitable for widespread use.

Whilst, generally still in their infancy, clinical data for effects of individual (or mixed) non- $\Delta^{9}$-THC pCBs may be usefully extended to trials for feeding-related disorders, neurodegenerative diseases, affective disorders and epilepsy, amongst others. This review has highlighted CBD, as a compound with a multi-modal mechanism of action, with clear therapeutic potential in a number of these areas, befitting its status as the second most prevalent pCB in cannabis (Lerner, 1963). In general, whilst it can be seen that large doses of CBD can be tolerated in humans, it is worth pointing out that formulation of CBD (or other pCBs), for example with lipid vehicles or dispersing surfactants, during potential drug development could substantially increase bioavailability. It is also apparent that other pCBs, such as $\Delta^{9}-\mathrm{THCV}$ and $\mathrm{CBG}$, may have a similar therapeutic potential, but that further preclinical work is needed to justify human trials. It is also clear that non- $\Delta^{9}-$ THC pCBs act at a wide range of molecular targets and may possess useful additional properties, such as anti-oxidant capacity, to support their pharmacological profile. A recurring issue is a pharmacological relevance of some of the pCB actions described herein; in this regard, pCBs typically exhibit functional responses with low micromolar potencies. A caveat here is that due to their high lipophilicity, for studies conducted in, for example, brain slice preparations, pCBs may partition into lipid membranes leading to underestimations of effective potency (discussed in Ma et al., 2008; see also Brown et al., 2004). Importantly, despite the relatively high concentrations required at some targets, pCBs such as $\Delta^{9}$-THCV and CBD are known to penetrate the blood-brain barrier well, with no major toxicity, genotoxicity, or mutagenicity (Hill et al., 2010a; Jones et al., 2010). Based on measurements of CSF levels in rat, we have calculated that $100 \mathrm{mg} / \mathrm{kg}$ CBD doses i.p. reach 
CNS concentrations of $\sim 18 \mu \mathrm{M}$ which suggests that low micromolar potencies can have functional relevance. In this regard, CBD doses as high as $1200 \mathrm{mg}$ have been safely tolerated in human trials (Trembly \& Sherman, 1990; see Table 1). Thus, the future of pCBs as safe and efficacious agents to combat CNS disease holds great pharmacological and therapeutic promise. 


\section{Acknowledgements}

The authors wish to thank researchers within the laboratory, in particular Dr Imogen Smith, Mr Nicholas Jones and Mr Jon Farrimond for data and input to the work. BJW thanks Dr Ethan Russo for valuable discussion and difficult to obtain manuscripts associated with cannabis effects upon epilepsy. BJW also thanks Prof. Elizabeth Williamson and Prof. Raphael Mechoulam for first kindling his interest in phytocannabinoid pharmacology. AJH thanks Prof. Javier Fernandez-Ruiz for a pre-publication view of data. The authors gratefully acknowledge funding support from GW Pharmaceuticals and Otsuka Pharmaceuticals, the Wellcome Trust (GJS), Ataxia UK (BJW/GJS) and The Royal Society (BJW and GJS).

\section{Figure legends}

Figure 1. Biosynthesis of major phytocannabinoids.

Figure 2. Effect of phytocannabinoids on SR141716A binding in mouse cerebellum membranes. Competition binding assays for phytocannabinoids in comparison to standard synthetic $\mathrm{CB}_{1}$ ligands against $1 \mathrm{nM}\left[{ }^{3} \mathrm{H}\right] \mathrm{SR} 141716 \mathrm{~A}$. B) $\Delta^{9}$-THCV has micromolar affinity and CBD and CBG have millimolar affinity for $\mathrm{CB}_{1}$ receptors.

Figure 3. Effect of $\Delta^{9}$-THCV in mouse cerebellar brain slices. A) In patch clamp recording from IN-PC synapses, $\Delta^{9}$-THCV $(58 \mu \mathrm{M})$ increased frequency of miniature inhibitory postsynaptic currents and blocked agonist effects of WIN55,212-2 (WIN55; $5 \mu \mathrm{M}$ ). B) In MEA recording from cerebellar slices (i), WIN55 (5 $\mu \mathrm{M})$-induced increases in PC spike firing were significantly reversed by $\Delta^{9}$-THCV $(5-40 \mu \mathrm{M}) ; * \mathrm{p}<0.05$ (Mann-Whitney U-test)

Figure 4. CBD has a multi-modal action. Scheme showing some identified molecular targets and potential modes of actions for CBD in central neurons. 
Table1: Summary of human case studies and clinical trials employing cannabinoids or cannabis in which a pro- or anti-convulsant effect was observed. The limited nature of some sources occasionally render information regarding study design, dosage routes, compound purity and origin unavailable. Extant and pertinent information has been included below.

\begin{tabular}{|c|c|c|c|c|c|}
\hline $\begin{array}{l}\text { Report } \\
\text { type }\end{array}$ & $\begin{array}{l}\text { Study } \\
\text { drug }\end{array}$ & $\begin{array}{l}\text { Pro- or anti- } \\
\text { convulsant }\end{array}$ & Primary outcome & Reference & Notes \\
\hline $\begin{array}{l}\text { Clinical } \\
\text { trial }\end{array}$ & $\Delta^{9}$-THC & $\begin{array}{l}\text { Anti- } \\
\text { convulsant }\end{array}$ & $\begin{array}{l}\text { 'severe anticonvulsant } \\
\text { resistant grand mal } \\
\text { epilepsy controlled' in } 2 / 5 \\
\text { children; no change to } 3 / 5 \\
\text { children. }\end{array}$ & $\begin{array}{l}\text { Davis \& } \\
\text { Ramsey } \\
(1949)\end{array}$ & $\begin{array}{l}\Delta^{9} \text {-THC administered to } 5 \\
\text { institutionalised children, } \\
\text { previously unresponsive to } \\
\text { phenobarbital and phenytoin. }\end{array}$ \\
\hline $\begin{array}{l}\text { Case } \\
\text { study }\end{array}$ & $\begin{array}{l}\text { Smoked } \\
\text { cannabis }\end{array}$ & $\begin{array}{l}\text { Anti- } \\
\text { convulsant }\end{array}$ & Full control of seizures & $\begin{array}{l}\text { Consroe et al. } \\
\text { (1975) }\end{array}$ & $\begin{array}{l}\text { Isolated report of one adult using } \\
\text { phenytoin and phenobarbital who } \\
\text { only achieved full seizure control } \\
\text { when also using smoked cannabis. } \\
\text { Seizures returned when phenytoin } \\
\text { and phenobarbital were withdrawn } \\
\text { and only cannabis smoked. }\end{array}$ \\
\hline $\begin{array}{l}\text { Clinical } \\
\text { trial }\end{array}$ & $\begin{array}{l}\text { Oral } \\
\text { CBD } \\
(\leq 300 \\
\text { mg per } \\
\text { day })\end{array}$ & $\begin{array}{l}\text { Anti- } \\
\text { convulsant }\end{array}$ & $\begin{array}{l}\text { 4/8 CBD treated patients } \\
\text { with full seizure control, } \\
1 / 8 \text { improved markedly, } \\
2 / 8 \text { improved somewhat, } \\
1 / 8 \text { no improvement. } \\
\text { In placebo-treated patients } \\
1 / 8 \text { showed a little } \\
\text { improvement, } 7 / 8 \text { showed } \\
\text { no change. }\end{array}$ & $\begin{array}{l}\text { Carlini \& } \\
\text { Cunha (1981) }\end{array}$ & $\begin{array}{l}\text { Small (15), adult patient cohort all } \\
\text { with partial seizures with secondary } \\
\text { generalisation that were } \\
\text { unresponsive to conventional } \\
\text { treatment; double blind study } \\
\text { design employing CBD and } \\
\text { placebo. }\end{array}$ \\
\hline $\begin{array}{l}\text { Clinical } \\
\text { trial }\end{array}$ & $\begin{array}{l}\text { Oral } \\
\text { CBD } \\
(200-300 \\
\text { mg per } \\
\text { day) }\end{array}$ & No change & $\begin{array}{l}\text { No significant change to } \\
\text { seizure incidence }\end{array}$ & $\begin{array}{l}\text { Ames \& } \\
\text { Cridland } \\
(1986)\end{array}$ & $\begin{array}{l}\text { Findings only published in abstract } \\
\text { form which yields limited } \\
\text { information; } 12 \text { patients enrolled; } \\
\text { CBD given as an adjunct to existing } \\
\text { treatments. }\end{array}$ \\
\hline $\begin{array}{l}\text { Survey } \\
\text { of } \\
\text { cannabis } \\
\text { use in } \\
\text { patients } \\
\text { admitted } \\
\text { to } \\
\text { hospital } \\
\text { after first } \\
\text { seizure }\end{array}$ & Cannabis & $\begin{array}{l}\text { Anti- } \\
\text { convulsant }\end{array}$ & $\begin{array}{l}\text { The authors concluded that } \\
\text { 'marijuana use [is] a } \\
\text { protective factor for new- } \\
\text { onset seizures' }\end{array}$ & $\begin{array}{l}\text { Ng et al. } \\
\text { (1990) }\end{array}$ & $\begin{array}{l}\text { Survey of } 308 \text { patients admitted to } \\
\text { hospital after first seizure compared } \\
\text { to } 294 \text { control patients with no } \\
\text { seizure; the results were criticised } \\
\text { as 'weak' by a } 1999 \text { US Institute of } \\
\text { Medicine report 'Marijuana and } \\
\text { medicine: Assessing the science } \\
\text { base' since 'the study did not } \\
\text { include measures of health status } \\
\text { prior to hospital admissions and } \\
\text { differences in their health status } \\
\text { might have influenced their drug } \\
\text { use' }\end{array}$ \\
\hline
\end{tabular}




\begin{tabular}{|c|c|c|c|c|c|}
\hline $\begin{array}{l}\text { Clinical } \\
\text { trial }\end{array}$ & $\begin{array}{l}\text { CBD } \\
(900- \\
1200 \mathrm{mg} \\
\text { per day } \\
\text { for } 10 \\
\text { months })\end{array}$ & $\begin{array}{l}\text { Anti- } \\
\text { convulsant }\end{array}$ & $\begin{array}{l}\text { 'seizure frequency was } \\
\text { markedly reduced in the } \\
\text { patient' }\end{array}$ & $\begin{array}{l}\text { Trembly \& } \\
\text { Sherman } \\
(1990)\end{array}$ & $\begin{array}{l}\text { Open label clinical trial; Results } \\
\text { presented at conference and cited } \\
\text { in: British Medical Association. } \\
\text { Therapeutic uses of cannabis. } \\
\text { Harwood Academic Publishers, } \\
\text { Amsterdam, 1997; p51 }\end{array}$ \\
\hline $\begin{array}{l}\text { Case } \\
\text { studies }\end{array}$ & Cannabis & $\begin{array}{l}\text { Anti- } \\
\text { convulsant }\end{array}$ & $\begin{array}{l}\text { Qualitative reports of } \\
\text { successful seizure control } \\
\text { with cannabis in three } \\
\text { epilepsy patients }\end{array}$ & $\begin{array}{l}\text { Grinspoon \& } \\
\text { Bakalar } \\
(1997)\end{array}$ & \\
\hline $\begin{array}{l}\text { Case } \\
\text { studies }\end{array}$ & Cannabis & $\begin{array}{c}\text { Anti- } \\
\text { convulsant }\end{array}$ & $\begin{array}{l}\text { Qualitative reports of } 11 \\
\text { patients successfully self- } \\
\text { treating seizures with } \\
\text { cannabis }\end{array}$ & Petro (1997) & $\begin{array}{l}\text { Patients identified as applicants to } \\
\text { the US Compassionate Use } \\
\text { Investigational New Drug } \\
\text { Programme to provide legal } \\
\text { medical exemption from } \\
\text { prosecution for cannabis possession } \\
\text { and use. }\end{array}$ \\
\hline Survey & Cannabis & $\begin{array}{l}\text { Anti- } \\
\text { convulsant }\end{array}$ & $\begin{array}{l}4 \% \text { of patients supported } \\
\text { by a medical marihuana } \\
\text { programme reported use } \\
\text { for seizure control }\end{array}$ & Corral (2001) & Survey population size: 77 \\
\hline Survey & Cannabis & $\begin{array}{l}\text { Anti- } \\
\text { convulsant }\end{array}$ & $\begin{array}{l}1 \% \text { of clinical cannabis } \\
\text { users in California reported } \\
\text { use for seizure control }\end{array}$ & $\begin{array}{l}\text { Gieringer } \\
(2001)\end{array}$ & Survey population size: $\sim 2500$ \\
\hline Survey & $\begin{array}{l}\text { Cannabis } \\
\text { and } \Delta^{9}- \\
\text { THC }\end{array}$ & $\begin{array}{l}\text { Anti- } \\
\text { convulsant }\end{array}$ & $\begin{array}{l}1.4 \% \text { of German medical } \\
\text { users of cannabis and THC } \\
\text { reported use for seizure } \\
\text { control }\end{array}$ & $\begin{array}{l}\text { Grotenhermen } \\
\text { \& Schnelle } \\
(2003)\end{array}$ & Survey population size: 143 \\
\hline $\begin{array}{l}\text { Case } \\
\text { studies }\end{array}$ & $\Delta^{9}-\mathrm{THC}$ & $\begin{array}{c}\text { Anti- } \\
\text { convulsant }\end{array}$ & 'Anticonvulsive action' & Lorenz (2004) & $\begin{array}{l}0.04-0.12 \mathrm{mg} / \mathrm{kg} \text { administered } \\
\text { orally }\end{array}$ \\
\hline Survey & Cannabis & $\begin{array}{l}\text { Anti- } \\
\text { convulsant }\end{array}$ & $\begin{array}{l}\text { 'The majority of active } \\
\text { users } \text { [reported] beneficial } \\
\text { effects on seizures' }\end{array}$ & $\begin{array}{l}\text { Gross et al., } \\
(2004)\end{array}$ & $\begin{array}{l}\text { Telephone survey of epilepsy } \\
\text { patients }\end{array}$ \\
\hline Survey & Cannabis & $\begin{array}{l}\text { Anti- } \\
\text { convulsant }\end{array}$ & $\begin{array}{l}\text { Dutch Ministry of Health } \\
\text { ordered (1999) monitoring } \\
\text { of } \Delta^{9} \text {-THC content of all } \\
\text { legally supplied cannabis } \\
\text { following reports of } \\
\text { reduced seizure duration } \\
\text { and incidence in cannabis } \\
\text { users. }\end{array}$ & $\begin{array}{l}\text { Pijlman et al. } \\
(2005)\end{array}$ & \\
\hline $\begin{array}{l}\text { Clinical } \\
\text { trial }\end{array}$ & $\begin{array}{l}\Delta^{9} \mathrm{THC} \\
/ \mathrm{CBD} \\
\text { (Sativex) }\end{array}$ & $\begin{array}{l}\text { Pro- } \\
\text { convulsant }\end{array}$ & $\begin{array}{l}\text { Four patients experienced } \\
\text { 'first ever seizures' }\end{array}$ & $\begin{array}{l}\text { Wade } \text { et al. } \\
\text { (2006) }\end{array}$ & $\begin{array}{l}\text { Open label clinical trial in multiple } \\
\text { sclerosis patients }\end{array}$ \\
\hline $\begin{array}{l}\text { Case } \\
\text { study }\end{array}$ & Cannabis & $\begin{array}{l}\text { Anti- } \\
\text { convulsant }\end{array}$ & $\begin{array}{l}\text { 'Marked improvement' in } \\
\text { seizure control following } \\
\text { marijuana use }\end{array}$ & $\begin{array}{l}\text { Mortati et al. } \\
\text { (2007) }\end{array}$ & Adult cerebral palsy patient \\
\hline
\end{tabular}




\section{REFERENCES}

Abood, M. E., Rizvi, G., Sallapudi, N. \& Mcallister, S. D. (2001). Activation of the CB1 cannabinoid receptor protects cultured mouse spinal neurons against excitotoxicity. Neurosci Lett, 309, 197-201.

Agosti, V., Nunes, E. \& Levin, F. (2002). Rates of psychiatric comorbidity among U.S. residents with lifetime cannabis dependence. Am J Drug Alcohol Abuse, 28, 643-652.

Ahrens, J., Demir, R., Leuwer, M., De La Roche, J., Krampfl, K., Foadi, N., et al. (2009). The nonpsychotropic cannabinoid cannabidiol modulates and directly activates alpha-1 and alpha-1-Beta glycine receptor function. Pharmacology, 83, 217-222.

Alger, B. E. \& Kim, J. (2011). Supply and demand for endocannabinoids. Trends Neurosci, 34, 304-315.

Ames, F. R. \& Cridland, S. (1986). Anticonvulsant effect of cannabidiol. S Afr Med J, 69, 14.

Arevalo-Martin, A., Garcia-Ovejero, D., Gomez, O., Rubio-Araiz, A., Navarro-Galve, B., Guaza, C., et al. (2008). CB2 cannabinoid receptors as an emerging target for demyelinating diseases: from neuroimmune interactions to cell replacement strategies. Br J Pharmacol, 153, 216-225.

Arevalo-Martin, A., Vela, J. M., Molina-Holgado, E., Borrell, J. \& Guaza, C. (2003). Therapeutic action of cannabinoids in a murine model of multiple sclerosis. J Neurosci, 23, 2511-2516.

Arnold, J. C., Hunt, G. E. \& Mcgregor, I. S. (2001). Effects of the cannabinoid receptor agonist CP 55,940 and the cannabinoid receptor antagonist SR 141716 on intracranial selfstimulation in Lewis rats. Life Sci, 70, 97-108.

Ashton, C. H. (2001). Pharmacology and effects of cannabis: a brief review. Br J Psychiatry, 178, 101-106.

Ashton, H., Golding, J., Marsh, V. R., Millman, J. E. \& Thompson, J. W. (1981). The seed and the soil: effect of dosage, personality and starting state on the response to delta 9 tetrahydrocannabinol in man. Br J Clin Pharmacol, 12, 705-720.

Baker, D., Pryce, G., Croxford, J. L., Brown, P., Pertwee, R. G., Huffman, J. W., et al. (2000). Cannabinoids control spasticity and tremor in a multiple sclerosis model. Nature, 404, 84-87. 
Beal, J. E., Olson, R., Laubenstein, L., Morales, J. O., Bellman, P., Yangco, B., et al. (1995). Dronabinol as a treatment for anorexia associated with weight loss in patients with AIDS. J Pain Symptom Manage, 10, 89-97.

Bergamaschi, M. M., Queiroz, R. H., Chagas, M. H., De Oliveira, D. C., De Martinis, B. S., Kapczinski, F., et al. (2011). Cannabidiol reduces the anxiety induced by simulated public speaking in treatment-naive social phobia patients. Neuropsychopharmacology, 36, 1219-1226.

Bisogno, T., Hanus, L., De Petrocellis, L., Tchilibon, S., Ponde, D. E., Brandi, I., et al. (2001). Molecular targets for cannabidiol and its synthetic analogues: effect on vanilloid VR1 receptors and on the cellular uptake and enzymatic hydrolysis of anandamide. $\mathrm{Br} J$ Pharmacol, 134, 845-852.

Bitencourt, R. M., Pamplona, F. A. \& Takahashi, R. N. (2008). Facilitation of contextual fear memory extinction and anti-anxiogenic effects of AM404 and cannabidiol in conditioned rats. Eur Neuropsychopharmacol, 18, 849-859.

Blazquez, C., Chiarlone, A., Sagredo, O., Aguado, T., Pazos, M. R., Resel, E., et al. (2011). Loss of striatal type 1 cannabinoid receptors is a key pathogenic factor in Huntington's disease. Brain, 134, 119-136.

Boggan, W. O., Steele, R. A. \& Freedman, D. X. (1973). 9 -Tetrahydrocannabinol effect on audiogenic seizure susceptibility. Psychopharmacologia, 29, 101-106.

Bolognini, D., Costa, B., Maione, S., Comelli, F., Marini, P., Di Marzo, V., et al. (2010). The plant cannabinoid Delta9-tetrahydrocannabivarin can decrease signs of inflammation and inflammatory pain in mice. Br J Pharmacol, 160, 677-687.

Bornheim, L. M. \& Grillo, M. P. (1998). Characterization of cytochrome P450 3A inactivation by cannabidiol: possible involvement of cannabidiol-hydroxyquinone as a P450 inactivator. Chem Res Toxicol, 11, 1209-1216.

British Medical Association (1997). Therapeutic uses of cannabis. Harwood Academic, Australia.

Brown, S. P., Safo, P. K. \& Regehr, W. G. (2004). Endocannabinoids inhibit transmission at granule cell to Purkinje cell synapses by modulating three types of presynaptic calcium channels. J Neurosci, 24, 5623-5631. 
Buckner, J. D. \& Schmidt, N. B. (2008). Marijuana effect expectancies: relations to social anxiety and marijuana use problems. Addict Behav, 33, 1477-1483.

Cabral, G. A. \& Griffin-Thomas, L. (2009). Emerging role of the cannabinoid receptor CB2 in immune regulation: therapeutic prospects for neuroinflammation. Expert Rev Mol Med, $11, \mathrm{e} 3$.

Carlini, E. A. \& Cunha, J. M. (1981). Hypnotic and antiepileptic effects of cannabidiol. J Clin Pharmacol, 21, 417S-427S.

Carrier, E. J., Auchampach, J. A. \& Hillard, C. J. (2006). Inhibition of an equilibrative nucleoside transporter by cannabidiol: a mechanism of cannabinoid immunosuppression. Proc Natl Acad Sci U S A, 103, 7895-7900.

Carrier, E. J., Kearn, C. S., Barkmeier, A. J., Breese, N. M., Yang, W., Nithipatikom, K., et al. (2004). Cultured rat microglial cells synthesize the endocannabinoid 2arachidonylglycerol, which increases proliferation via a CB2 receptor-dependent mechanism. Mol Pharmacol, 65, 999-1007.

Carroll, C. B., Bain, P. G., Teare, L., Liu, X., Joint, C., Wroath, C., et al. (2004). Cannabis for dyskinesia in Parkinson disease: a randomized double-blind crossover study. Neurology, $63,1245-1250$.

Cascio, M. G., Gauson, L. A., Stevenson, L. A., Ross, R. A. \& Pertwee, R. G. (2010). Evidence that the plant cannabinoid cannabigerol is a highly potent alpha2-adrenoceptor agonist and moderately potent 5HT1A receptor antagonist. Br J Pharmacol, 159, 129-141.

Cat, L. K. \& Coleman, R. L. (1994). Treatment for HIV wasting syndrome. Ann Pharmacother, 28, 595-597.

Chaperon, F., Soubrie, P., Puech, A. J. \& Thiebot, M. H. (1998). Involvement of central cannabinoid (CB1) receptors in the establishment of place conditioning in rats. Psychopharmacology (Berl), 135, 324-332.

Chen, Y. \& Buck, J. (2000). Cannabinoids protect cells from oxidative cell death: a receptorindependent mechanism. J Pharmacol Exp Ther, 293, 807-812.

Chevaleyre, V., Takahashi, K. A. \& Castillo, P. E. (2006). Endocannabinoid-mediated synaptic plasticity in the CNS. Annu Rev Neurosci, 29, 37-76. 
Chopra, R.N. \& Chopra, G.S. (1939). The present position of hemp drug addiction in India. Ind. Med. Res. Mem, 31, 1-119.

Chiu, P., Karler, R., Craven, C., Olsen, D. M. \& Turkanis, S. A. (1975). The influence of delta9tetrahydrocannabinol, cannabinol and cannabidiol on tissue oxygen consumption. Res Commun Chem Pathol Pharmacol, 12, 267-286.

Chiu, P., Olsen, D. M., Borys, H. K., Karler, R. \& Turkanis, S. A. (1979). The influence of cannabidiol and delta 9-tetrahydrocannabinol on cobalt epilepsy in rats. Epilepsia, 20, $365-375$.

Christensen, R., Kristensen, P. K., Bartels, E. M., Bliddal, H. \& Astrup, A. (2007). Efficacy and safety of the weight-loss drug rimonabant: a meta-analysis of randomised trials. Lancet, 370, 1706-1713.

Clinical Neurology Research Group (2009). CUPID. In. Exeter \& Plymotuh: CNRG.

Colasanti, B. K., Lindamood, C., 3rd \& Craig, C. R. (1982). Effects of marihuana cannabinoids on seizure activity in cobalt-epileptic rats. Pharmacol Biochem Behav, 16, 573-578.

Collin, C., Davies, P., Mutiboko, I. K. \& Ratcliffe, S. (2007). Randomized controlled trial of cannabis-based medicine in spasticity caused by multiple sclerosis. Eur J Neurol, 14, 290-296.

Compston, A. \& Coles, A. (2008). Multiple sclerosis. Lancet, 372, 1502-1517.

Consroe, P., Benedito, M. A., Leite, J. R., Carlini, E. A. \& Mechoulam, R. (1982). Effects of cannabidiol on behavioral seizures caused by convulsant drugs or current in mice. Eur $J$ Pharmacol, 83, 293-298.

Consroe, P. \& Fish, B. S. (1980). Behavioral pharmacology of tetrahydrocannabinol convulsions in rabbits. Commun Psychopharmacol, 4, 287-291.

Consroe, P., Laguna, J., Allender, J., Snider, S., Stern, L., Sandyk, R., et al. (1991). Controlled clinical trial of cannabidiol in Huntington's disease. Pharmacol Biochem Behav, 40, 701708.

Consroe, P., Martin, A. \& Singh, V. (1981). Antiepileptic potential of cannabidiol analogs. $J$ Clin Pharmacol, 21, 428S-436S.

Consroe, P. \& Mechoulam, R. (1987). Anticonvulsant and neurotoxic effects of tetrahydrocannabinol stereoisomers. NIDA Res Monogr, 79, 59-66. 
Consroe, P., Sandyk, R. \& Snider, S. R. (1986). Open label evaluation of cannabidiol in dystonic movement disorders. Int J Neurosci, 30, 277-282.

Consroe, P. \& Wolkin, A. (1977a). Cannabidiol--antiepileptic drug comparisons and interactions in experimentally induced seizures in rats. J Pharmacol Exp Ther, 201, 26-32.

Consroe, P. F. \& Wolkin, A. L. (1977b). Anticonvulsant interaction of cannabidiol and ethosuximide in rats. $J$ Pharm Pharmacol, 29, 500-501.

Consroe, P. F., Wood, G. C. \& Buchsbaum, H. (1975). Anticonvulsant nature of marihuana smoking. JAMA, 234, 306-307.

Corral, V. (2001). Differential effects of medical marijuana based on strain and route of administration: a three-year observational study. J Cannabis Ther, 1, 43-59.

Costa, B., Giagnoni, G., Franke, C., Trovato, A. E. \& Colleoni, M. (2004). Vanilloid TRPV1 receptor mediates the antihyperalgesic effect of the nonpsychoactive cannabinoid, cannabidiol, in a rat model of acute inflammation. Br J Pharmacol, 143, 247-250.

Cota, D., Marsicano, G., Lutz, B., Vicennati, V., Stalla, G. K., Pasquali, R., et al. (2003). Endogenous cannabinoid system as a modulator of food intake. Int J Obes Relat Metab Disord, 27, 289-301.

Cravatt, B. F., Giang, D. K., Mayfield, S. P., Boger, D. L., Lerner, R. A. \& Gilula, N. B. (1996). Molecular characterization of an enzyme that degrades neuromodulatory fatty-acid amides. Nature, 384, 83-87.

Crippa, J. A., Derenusson, G. N., Ferrari, T. B., Wichert-Ana, L., Duran, F. L., Martin-Santos, R., et al. (2011). Neural basis of anxiolytic effects of cannabidiol (CBD) in generalized social anxiety disorder: a preliminary report. J Psychopharmacol, 25, 121-130.

Crippa, J. A., Zuardi, A. W., Garrido, G. E., Wichert-Ana, L., Guarnieri, R., Ferrari, L., et al. (2004). Effects of cannabidiol (CBD) on regional cerebral blood flow. Neuropsychopharmacology, 29, 417-426.

Crippa, J. A., Zuardi, A. W., Martin-Santos, R., Bhattacharyya, S., Atakan, Z., Mcguire, P., et al. (2009). Cannabis and anxiety: a critical review of the evidence. Hum Psychopharmacol, 24, 515-523.

Cristino, L., Starowicz, K., De Petrocellis, L., Morishita, J., Ueda, N., Guglielmotti, V., et al. (2008). Immunohistochemical localization of anabolic and catabolic enzymes for 
anandamide and other putative endovanilloids in the hippocampus and cerebellar cortex of the mouse brain. Neuroscience, 151, 955-968.

Croxford, J. L. \& Miller, S. D. (2003). Immunoregulation of a viral model of multiple sclerosis using the synthetic cannabinoid R+WIN55,212. J Clin Invest, 111, 1231-1240.

Curtis, A., Mitchell, I., Patel, S., Ives, N. \& Rickards, H. (2009). A pilot study using nabilone for symptomatic treatment in Huntington's disease. Mov Disord, 24, 2254-2259.

Davis, J. P. \& Ramsey, H. H. (1949). Antiepileptic action of marijuana-active substances. Federation Proceedings, Baltimore, 8, 284-285.

De Meijer, E. P., Bagatta, M., Carboni, A., Crucitti, P., Moliterni, V. M., Ranalli, P., et al. (2003). The inheritance of chemical phenotype in Cannabis sativa L. Genetics, 163, 335-346.

Demuth, D. G. \& Molleman, A. (2006). Cannabinoid signalling. Life Sci, 78, 549-563.

De Petrocellis, L., Ligresti, A., Moriello, A. S., Allara, M., Bisogno, T., Petrosino, S., et al. (2011). Effects of cannabinoids and cannabinoid-enriched Cannabis extracts on TRP channels and endocannabinoid metabolic enzymes. Br J Pharmacol, 163, 1479-1494.

De Petrocellis, L., Vellani, V., Schiano-Moriello, A., Marini, P., Magherini, P. C., Orlando, P., et al. (2008). Plant-derived cannabinoids modulate the activity of transient receptor potential channels of ankyrin type-1 and melastatin type-8. J Pharmacol Exp Ther, 325, 1007-1015.

Dennis, I., Whalley, B. J. \& Stephens, G. J. (2008). Effects of Delta9-tetrahydrocannabivarin on [35S]GTPgammaS binding in mouse brain cerebellum and piriform cortex membranes. Br J Pharmacol, 154, 1349-1358.

Denson, T. F. \& Earleywine, M. (2006). Decreased depression in marijuana users. Addict Behav, $31,738-742$.

Deroche-Gamonet, V., Le Moal, M., Piazza, P. V. \& Soubrie, P. (2001). SR141716, a CB1 receptor antagonist, decreases the sensitivity to the reinforcing effects of electrical brain stimulation in rats. Psychopharmacology (Berl), 157, 254-259.

Desanty, K. P. \& Dar, M. S. (2001a). Cannabinoid-induced motor incoordination through the cerebellar CB(1) receptor in mice. Pharmacol Biochem Behav, 69, 251-259. 
Desanty, K. P. \& Dar, M. S. (2001b). Involvement of the cerebellar adenosine A(1) receptor in cannabinoid-induced motor incoordination in the acute and tolerant state in mice. Brain Res, 905, 178-187.

Devane, W. A., Hanus, L., Breuer, A., Pertwee, R. G., Stevenson, L. A., Griffin, G., et al. (1992). Isolation and structure of a brain constituent that binds to the cannabinoid receptor. Science, 258, 1946-1949.

Deyo, R. \& Musty, R. (2003). A cannabichromene (CBC) extract alters behavioral despair on the mouse tail suspension test of depression. 2003 Symposium on the Cannabinoids, International Cannabinoid Research Society, Burlington, VT, p.147.

Di Marzo, V. (2008). Targeting the endocannabinoid system: to enhance or reduce? Nat Rev Drug Discov, 7, 438-455.

Di Marzo, V. (2009). The endocannabinoid system: its general strategy of action, tools for its pharmacological manipulation and potential therapeutic exploitation. Pharmacol Res, 60, 77-84.

Di Marzo, V., De Petrocellis, L. \& Bisogno, T. (2005). The biosynthesis, fate and pharmacological properties of endocannabinoids. Handb Exp Pharmacol, 147-185.

Di Marzo, V., Fontana, A. (1995). Anandamide, an endogenous cannabinomimetic eicosanoid: 'killing two birds with one stone'. Prostaglandins Leukot Essent Fatty Acids, 53, 1-11

Di Marzo, V., Ligresti, A. \& Cristino, L. (2009). The endocannabinoid system as a link between homoeostatic and hedonic pathways involved in energy balance regulation. Int J Obes (Lond), 33 Suppl 2, S18-24.

Docagne, F., Muneton, V., Clemente, D., Ali, C., Loria, F., Correa, F., et al. (2007). Excitotoxicity in a chronic model of multiple sclerosis: Neuroprotective effects of cannabinoids through CB1 and CB2 receptor activation. Mol Cell Neurosci, 34, 551-561.

Dorard, G., Berthoz, S., Phan, O., Corcos, M. \& Bungener, C. (2008). Affect dysregulation in cannabis abusers: a study in adolescents and young adults. Eur Child Adolesc Psychiatry, 17, 274-282.

Dowie, M. J., Howard, M. L., Nicholson, L. F., Faull, R. L., Hannan, A. J. \& Glass, M. (2010). Behavioural and molecular consequences of chronic cannabinoid treatment in Huntington's disease transgenic mice. Neuroscience, 170, 324-336. 
Dumont, M. \& Beal, M. F. (2011). Neuroprotective strategies involving ROS in Alzheimer disease. Free Radic Biol Med, 51, 1014-1026.

Echegoyen, J., Armstrong, C., Morgan, R. J. \& Soltesz, I. (2009). Single application of a CB1 receptor antagonist rapidly following head injury prevents long-term hyperexcitability in a rat model. Epilepsy Res, 85, 123-127.

Ehrhart, J., Obregon, D., Mori, T., Hou, H., Sun, N., Bai, Y., et al. (2005). Stimulation of cannabinoid receptor 2 (CB2) suppresses microglial activation. J Neuroinflammation, 2, 29.

El-Alfy, A. T., Ivey, K., Robinson, K., Ahmed, S., Radwan, M., Slade, D., et al. (2010). Antidepressant-like effect of delta9-tetrahydrocannabinol and other cannabinoids isolated from Cannabis sativa L. Pharmacol Biochem Behav, 95, 434-442.

El-Remessy, A. B., Khalil, I. E., Matragoon, S., Abou-Mohamed, G., Tsai, N. J., Roon, P., et al. (2003). Neuroprotective effect of (-)Delta9-tetrahydrocannabinol and cannabidiol in Nmethyl-D-aspartate-induced retinal neurotoxicity: involvement of peroxynitrite. Am J Pathol, 163, 1997-2008.

Ellis, J. M. (2005). Cholinesterase inhibitors in the treatment of dementia. J Am Osteopath Assoc, $105,145-158$.

Elsohly, M. A. \& Slade, D. (2005). Chemical constituents of marijuana: the complex mixture of natural cannabinoids. Life Sci, 78, 539-548.

Esposito, G., De Filippis, D., Maiuri, M. C., De Stefano, D., Carnuccio, R. \& Iuvone, T. (2006). Cannabidiol inhibits inducible nitric oxide synthase protein expression and nitric oxide production in beta-amyloid stimulated PC12 neurons through p38 MAP kinase and NFkappaB involvement. Neurosci Lett, 399, 91-95.

Esposito, G., Scuderi, C., Savani, C., Steardo, L., Jr., De Filippis, D., Cottone, P., et al. (2007). Cannabidiol in vivo blunts beta-amyloid induced neuroinflammation by suppressing IL1beta and iNOS expression. Br J Pharmacol, 151, 1272-1279.

Eubanks, L. M., Rogers, C. J., Beuscher, A. E. T., Koob, G. F., Olson, A. J., Dickerson, T. J., et al. (2006). A molecular link between the active component of marijuana and Alzheimer's disease pathology. Mol Pharm, 3, 773-777. 
Farrimond, J. A., Hill, A. J., Whalley, B. J. \& Williams, C. M. (2010a). Cannabis constituents modulate delta9-tetrahydrocannabinol-induced hyperphagia in rats. Psychopharmacology (Berl), 210, 97-106.

Farrimond, J. A., Mercier, M. S., Whalley, B. J. \& Williams, C. M. (2011). Cannabis sativa and the endogenous cannabinoid system: therapeutic potential for appetite regulation. Phytother Res, 25, 170-188.

Farrimond, J. A., Whalley, B. J. \& Williams, C. M. (2010b). A low-Delta9tetrahydrocannabinol cannabis extract induces hyperphagia in rats. Behav Pharmacol.

Felder, C. C., Briley, E. M., Axelrod, J., Simpson, J. T., Mackie, K. \& Devane, W. A. (1993). Anandamide, an endogenous cannabimimetic eicosanoid, binds to the cloned human cannabinoid receptor and stimulates receptor-mediated signal transduction. Proc Natl Acad Sci U S A, 90, 7656-7660.

Fergusson, D. M. \& Horwood, L. J. (1997). Early onset cannabis use and psychosocial adjustment in young adults. Addiction, 92, 279-296.

Fish, B. S., Consroe, P. \& Fox, R. R. (1983). Convulsant-anticonvulsant properties of delta-9tetrahydrocannabinol in rabbits. Behav Genet, 13, 205-211.

Foadi, N., Leuwer, M., Demir, R., Dengler, R., Buchholz, V., De La Roche, J., et al. (2010). Lack of positive allosteric modulation of mutated alpha(1)S267I glycine receptors by cannabinoids. Naunyn Schmiedebergs Arch Pharmacol, 381, 477-482.

Foltin, R. W., Brady, J. V. \& Fischman, M. W. (1986). Behavioral analysis of marijuana effects on food intake in humans. Pharmacol Biochem Behav, 25, 577-582.

Foltin, R. W., Fischman, M. W. \& Byrne, M. F. (1988). Effects of smoked marijuana on food intake and body weight of humans living in a residential laboratory. Appetite, 11, 1-14.

Food and Drug Administration (2004). Guidance for industry: Botanical drug products.

Fox, S. H., Henry, B., Hill, M., Crossman, A. \& Brotchie, J. (2002). Stimulation of cannabinoid receptors reduces levodopa-induced dyskinesia in the MPTP-lesioned nonhuman primate model of Parkinson's disease. Mov Disord, 17, 1180-1187.

Fusar-Poli, P., Crippa, J. A., Bhattacharyya, S., Borgwardt, S. J., Allen, P., Martin-Santos, R., et al. (2009). Distinct effects of \{delta\}9-tetrahydrocannabinol and cannabidiol on neural activation during emotional processing. Arch Gen Psychiatry, 66, 95-105. 
Gallate, J. E. \& Mcgregor, I. S. (1999). The motivation for beer in rats: effects of ritanserin, naloxone and SR 141716. Psychopharmacology (Berl), 142, 302-308.

Gallate, J. E., Saharov, T., Mallet, P. E. \& Mcgregor, I. S. (1999). Increased motivation for beer in rats following administration of a cannabinoid CB1 receptor agonist. Eur J Pharmacol, $370,233-240$.

Gaoni, Y. \& Mechoulam, R. (1971). The isolation and structure of delta-1-tetrahydrocannabinol and other neutral cannabinoids from hashish. J Am Chem Soc, 93, 217-224.

Garcia-Arencibia, M., Ferraro, L., Tanganelli, S. \& Fernandez-Ruiz, J. (2008). Enhanced striatal glutamate release after the administration of rimonabant to 6-hydroxydopamine-lesioned rats. Neurosci Lett, 438, 10-13.

Garcia-Arencibia, M., Gonzalez, S., De Lago, E., Ramos, J. A., Mechoulam, R. \& FernandezRuiz, J. (2007). Evaluation of the neuroprotective effect of cannabinoids in a rat model of Parkinson's disease: importance of antioxidant and cannabinoid receptor-independent properties. Brain Res, 1134, 162-170.

Garcia, C., Palomo, C., Garcia-Arencibia, M., Ramos, J. A., Pertwee, R. G. \& Fernandez-Ruiz, J. (2011). Symptom-relieving and neuroprotective effects of the phytocannabinoid $\mathrm{D}(9)$ THCV in animal models of Parkinson's disease. Br J Pharmacol.

Gieringer, D. 2001. Medical use of cannabis: experience in California, Binghamton, NY, Haworth Press.

Gil, J. M. \& Rego, A. C. (2008). Mechanisms of neurodegeneration in Huntington's disease. Eur J Neurosci, 27, 2803-2820.

Gilbert, G. L., Kim, H. J., Waataja, J. J. \& Thayer, S. A. (2007). Delta9-tetrahydrocannabinol protects hippocampal neurons from excitotoxicity. Brain Res, 1128, 61-69.

Golech, S. A., Mccarron, R. M., Chen, Y., Bembry, J., Lenz, F., Mechoulam, R., et al. (2004). Human brain endothelium: coexpression and function of vanilloid and endocannabinoid receptors. Brain Res Mol Brain Res, 132, 87-92.

Gonzalez, S., Scorticati, C., Garcia-Arencibia, M., De Miguel, R., Ramos, J. A. \& FernandezRuiz, J. (2006). Effects of rimonabant, a selective cannabinoid CB1 receptor antagonist, in a rat model of Parkinson's disease. Brain Res, 1073-1074, 209-219. 
Grinspoon, L. \& Bakalar, J. B. 1997. Marihuana, the forbidden medicine, New Haven, CT, Yale University Press.

Gowers, W. R. (1888). A manual of diseases of the nervous system. P. Blakiston Son \& Co., Philadelphia, PA.

Gross, H. Egbert M.H., Faden, V.B., et al. (1983). A double-blind trial of $\Delta^{9}$-THC in primary anorexia nervosa. J Clin Psychopharmacol, 3, 165-171.

Gross, D. W., Hamm, J., Ashworth, N. L. \& Quigley, D. (2004). Marijuana use and epilepsy: prevalence in patients of a tertiary care epilepsy center. Neurology, 62, 2095-2097.

Grotenhermen, F. \& Schnelle, M. (2003). Survey on the medical use of cannabis and THC in Germany. Journal of Cannabis Therapeutics, 3, 17-40.

Guggenhuber, S., Monory, K., Lutz, B. \& Klugmann, M. (2010). AAV vector-mediated overexpression of CB1 cannabinoid receptor in pyramidal neurons of the hippocampus protects against seizure-induced excitoxicity. PLoS One, 5, e15707.

Guimaraes, F. S., Chiaretti, T. M., Graeff, F. G. \& Zuardi, A. W. (1990). Antianxiety effect of cannabidiol in the elevated plus-maze. Psychopharmacology (Berl), 100, 558-559.

GW Pharmaceuticals (2001). Investigator Brochure - Cannabis based medicine extract sublingual formulations.

Hallak, J. E., Dursun, S. M., Bosi, D. C., De Macedo, L. R., Machado-De-Sousa, J. P., Abrao, J., et al. (2011). The interplay of cannabinoid and NMDA glutamate receptor systems in humans: preliminary evidence of interactive effects of cannabidiol and ketamine in healthy human subjects. Prog Neuropsychopharmacol Biol Psychiatry, 35, 198-202.

Hampson, A. J., Grimaldi, M., Axelrod, J. \& Wink, D. (1998). Cannabidiol and (-)Delta9tetrahydrocannabinol are neuroprotective antioxidants. Proc Natl Acad Sci U S A, 95, 8268-8273.

Hasseldam, H. \& Johansen, F. F. (2010). Neuroprotection without immunomodulation is not sufficient to reduce first relapse severity in experimental autoimmune encephalomyelitis. Neuroimmunomodulation, 17, 252-264.

Herkenham, M., Lynn, A. B., Little, M. D., Johnson, M. R., Melvin, L. S., De Costa, B. R., et al. (1990). Cannabinoid receptor localization in brain. Proc Natl Acad Sci U S A, 87, 19321936. 
Hickson, M. (2006). Malnutrition in ageing. Postgrad Med J, 82, 2-8.

Higgs, S., Williams, C. M. \& Kirkham, T. C. (2003). Cannabinoid influences on palatability: microstructural analysis of sucrose drinking after delta(9)-tetrahydrocannabinol, anandamide, 2-arachidonoyl glycerol and SR141716. Psychopharmacology (Berl), 165, 370-377.

Hill, A. J., Weston, S. E., Jones, N. A., Smith, I., Bevan, S. A., Williamson, E. M., et al. (2010a). Delta-Tetrahydrocannabivarin suppresses in vitro epileptiform and in vivo seizure activity in adult rats. Epilepsia.

Hill A .J., Jones N. A., Stephens, G. J., Williams, C. M., Whalley, B. J. (2010b). Anticonvulsant effects of GWP42006 in vitro and in vivo in rat. Physiology 2010 Meeting abstract, University of Manchester, UK

Hindle, J. V. (2010). Ageing, neurodegeneration and Parkinson's disease. Age Ageing, 39, 156161.

Hollister, L. E. (1971). Hunger and appetite after single doses of marihuana, alcohol, and dextroamphetamine. Clin Pharmacol Ther, 12, 44-49.

Horswill, J. G., Bali, U., Shaaban, S., Keily, J. F., Jeevaratnam, P., Babbs, A. J., et al. (2007). PSNCBAM-1, a novel allosteric antagonist at cannabinoid CB1 receptors with hypophagic effects in rats. Br J Pharmacol, 152, 805-814.

House of Lords (1998). Cannabis: the scientific and medical evidence. Stationery office: House of Lords Committee on Science and Technology, London.

Howlett, A. C. (2002). The cannabinoid receptors. Prostaglandins Other Lipid Mediat, 68-69, 619-631.

Hurley, M. J., Mash, D. C. \& Jenner, P. (2003). Expression of cannabinoid CB1 receptor mRNA in basal ganglia of normal and parkinsonian human brain. J Neural Transm, 110, 12791288.

Ignatowska-Jankowska, B., Jankowski, M. M. \& Swiergiel, A. H. (2011). Cannabidiol decreases body weight gain in rats: involvement of CB2 receptors. Neurosci Lett, 490, 82-84.

Innamorati, M., Pompili, M., Ferrari, V., Girardi, P., Tatarelli, R., Tamburello, A., et al. (2008). Cannabis use and the risk behavior syndrome in Italian university students: are they related to suicide risk? Psychol Rep, 102, 577-594. 
Inui, A. (2002). Cancer anorexia-cachexia syndrome: current issues in research and management. CA Cancer J Clin, 52, 72-91.

Iskedjian, M., Bereza, B., Gordon, A., Piwko, C. \& Einarson, T. R. (2007). Meta-analysis of cannabis based treatments for neuropathic and multiple sclerosis-related pain. Curr Med Res Opin, 23, 17-24.

Iuvone, T., Esposito, G., Esposito, R., Santamaria, R., Di Rosa, M. \& Izzo, A. A. (2004). Neuroprotective effect of cannabidiol, a non-psychoactive component from Cannabis sativa, on beta-amyloid-induced toxicity in PC12 cells. J Neurochem, 89, 134-141.

Izzo, A. A., Borrelli, F., Capasso, R., Di Marzo, V. \& Mechoulam, R. (2009). Non-psychotropic plant cannabinoids: new therapeutic opportunities from an ancient herb. Trends Pharmacol Sci, 30, 515-527.

Jarvis, K., Delbello, M. P., Mills, N., Elman, I., Strakowski, S. M. \& Adler, C. M. (2008). Neuroanatomic comparison of bipolar adolescents with and without cannabis use disorders. J Child Adolesc Psychopharmacol, 18, 557-563.

Jones, N. A., Hill, A. J., Smith, I., Bevan, S. A., Williams, C. M., Whalley, B. J., et al. (2010). Cannabidiol displays antiepileptiform and antiseizure properties in vitro and in vivo. $J$ Pharmacol Exp Ther, 332, 569-577.

Kalant, H. (2001). Medicinal use of cannabis: history and current status. Pain Res Manag, 6, 8091.

Karler, R., Cely, W. \& Turkanis, S. A. (1973). The anticonvulsant activity of cannabidiol and cannabinol. Life Sci, 13, 1527-1531.

Karler, R., Cely, W. \& Turkanis, S. A. (1974a). Anticonvulsant activity of delta9tetrahydrocannabilol and its 11-hydroxy and 8alpha, 11-dihydroxy metabolites in the frog. Res Commun Chem Pathol Pharmacol, 9, 441-452.

Karler, R., Cely, W. \& Turkanis, S. A. (1974b). Anticonvulsant properties of delta 9tetrahydrocannabinol and other cannabinoids. Life Sci, 15, 931-947.

Karler, R. \& Turkanis, S. A. 1976. The antiepileptic potential of the cannabinoids, New York, Plenum Medical Book Company.

Karler, R. \& Turkanis, S. A. (1980). Subacute cannabinoid treatment: anticonvulsant activity and withdrawal excitability in mice. Br J Pharmacol, 68, 479-484. 
Karler, R. \& Turkanis, S. A. (1981). The cannabinoids as potential antiepileptics. J Clin Pharmacol, 21, 437S-448S.

Kelsey, J. E., Harris, O. \& Cassin, J. (2009). The CB(1) antagonist rimonabant is adjunctively therapeutic as well as monotherapeutic in an animal model of Parkinson's disease. Behav Brain Res, 203, 304-307.

Kirkham TC (2008). Endocannabinoids and the neurochemistry of gluttony. J Neuroendocrinol, 20, 1099-1100.

Kotin, J., Post, R. M. \& Goodwin, F. K. (1973). 9 -Tetrahydrocannabinol in depressed patients. Arch Gen Psychiatry, 28, 345-348.

Kozan, R., Ayyildiz, M. \& Agar, E. (2009). The effects of intracerebroventricular AM-251, a CB1-receptor antagonist, and ACEA, a CB1-receptor agonist, on penicillin-induced epileptiform activity in rats. Epilepsia, 50, 1760-1767.

Kozela, E., Pietr, M., Juknat, A., Rimmerman, N., Levy, R. \& Vogel, Z. (2010). Cannabinoids Delta(9)-tetrahydrocannabinol and cannabidiol differentially inhibit the lipopolysaccharide-activated NF-kappaB and interferon-beta/STAT proinflammatory pathways in BV-2 microglial cells. J Biol Chem, 285, 1616-1626.

Kreitzer, F. R. \& Stella, N. (2009). The therapeutic potential of novel cannabinoid receptors. Pharmacol Ther, 122, 83-96.

Krishnan, S., Cairns, R. \& Howard, R. (2009). Cannabinoids for the treatment of dementia. Cochrane Database Syst Rev, CD007204.

Kumar, P., Kalonia, H. \& Kumar, A. (2010). Huntington's disease: pathogenesis to animal models. Pharmacol Rep, 62, 1-14.

Lakhan, S. E. \& Rowland, M. (2009). Whole plant cannabis extracts in the treatment of spasticity in multiple sclerosis: a systematic review. BMC Neurol, 9, 59.

Lastres-Becker, I., Bizat, N., Boyer, F., Hantraye, P., Fernandez-Ruiz, J. \& Brouillet, E. (2004). Potential involvement of cannabinoid receptors in 3-nitropropionic acid toxicity in vivo. Neuroreport, 15, 2375-2379.

Lastres-Becker, I., Molina-Holgado, F., Ramos, J. A., Mechoulam, R. \& Fernandez-Ruiz, J. (2005). Cannabinoids provide neuroprotection against 6-hydroxydopamine toxicity in vivo and in vitro: relevance to Parkinson's disease. Neurobiol Dis, 19, 96-107. 
Ledgerwood, C. J., Greenwood, S. M., Brett, R. R., Pratt, J. A. \& Bushell, T. J. (2011).

Cannabidiol inhibits synaptic transmission in rat hippocampal cultures and slices via multiple receptor pathways. Br J Pharmacol, 162, 286-294.

Lee, H.K., Choi, E.B., Pak, C.S. (2009). The current status and future perspectives of studies of cannabinoid receptor 1 antagonists as anti-obesity agents. Curr Top Med Chem, 9, 482503.

Lee, Y. J., Han, S. B., Nam, S. Y., Oh, K. W. \& Hong, J. T. (2010). Inflammation and Alzheimer's disease. Arch Pharm Res, 33, 1539-1556.

Leppik, I. E. \& Birnbaum, A. K. (2010). Epilepsy in the elderly. Ann N Y Acad Sci, 1184, 208224.

Lerner, M. (1963). Marihuana: Tetrahydrocannabinol and Related Compounds. Science, 140, 175-176.

Li, H. L., \& Lin, H. (1974). An archaeological and historical account of cannabis in China. Econ Bot. 28(4), 437-447.

Liou, G. I., Auchampach, J. A., Hillard, C. J., Zhu, G., Yousufzai, B., Mian, S., et al. (2008). Mediation of cannabidiol anti-inflammation in the retina by equilibrative nucleoside transporter and A2A adenosine receptor. Invest Ophthalmol Vis Sci, 49, 5526-5531.

Lorenz, R. (2004). On the application of cannabis in paediatrics and epileptology. Neuro Endocrinol Lett, 25, 40-44.

Loscher, W. (1997). Animal models of intractable epilepsy. Prog Neurobiol, 53, 239-258.

Lozano, I. (2001). The therapeutic use of Cannabis sativa L. in Arabic medicine. Journal of Cannabis Therapeutics, 1, 63-70.

Lull, M. E. \& Block, M. L. (2010). Microglial activation and chronic neurodegeneration. Neurotherapeutics, 7, 354-365.

Lutz, B. (2004). On-demand activation of the endocannabinoid system in the control of neuronal excitability and epileptiform seizures. Biochem Pharmacol, 68, 1691-1698.

Lyman, W. D., Sonett, J. R., Brosnan, C. F., Elkin, R. \& Bornstein, M. B. (1989). Delta 9tetrahydrocannabinol: a novel treatment for experimental autoimmune encephalomyelitis. J Neuroimmunol, 23, 73-81. 
Ma, Y. L., Weston, S. E., Whalley, B. J. \& Stephens, G. J. (2008). The phytocannabinoid Delta(9)-tetrahydrocannabivarin modulates inhibitory neurotransmission in the cerebellum. Br J Pharmacol.

Magen, I., Avraham, Y., Ackerman, Z., Vorobiev, L., Mechoulam, R. \& Berry, E. M. (2009). Cannabidiol ameliorates cognitive and motor impairments in mice with bile duct ligation. J Hepatol, 51, 528-534.

Magen, I., Avraham, Y., Ackerman, Z., Vorobiev, L., Mechoulam, R. \& Berry, E. M. (2010). Cannabidiol ameliorates cognitive and motor impairments in bile-duct ligated mice via 5HT1A receptor activation. Br J Pharmacol, 159, 950-957.

Malone, D. T., Jongejan, D. \& Taylor, D. A. (2009). Cannabidiol reverses the reduction in social interaction produced by low dose Delta(9)-tetrahydrocannabinol in rats. Pharmacol Biochem Behav, 93, 91-96.

Maresz, K., Pryce, G., Ponomarev, E. D., Marsicano, G., Croxford, J. L., Shriver, L. P., et al. (2007). Direct suppression of CNS autoimmune inflammation via the cannabinoid receptor CB1 on neurons and CB2 on autoreactive T cells. Nat Med, 13, 492-497.

Martin-Moreno, A. M., Reigada, D., Ramirez, B. G., Mechoulam, R., Innamorato, N., Cuadrado, A., et al. (2011). Cannabidiol and other cannabinoids reduce microglial activation in vitro and in vivo: relevance to Alzheimers' disease. Mol Pharmacol.

Martin, A. R., Consroe, P., Kane, V. V., Shah, V., Singh, V., Lander, N., et al. (1987). Structureanticonvulsant activity relationships of cannabidiol analogs. NIDA Res Monogr, 79, 4858.

Martin, P. \& Consroe, P. (1978). Tolerance to delta9-tetrahydrocannabinol in adapted and nonadapted rabbits. Pharmacol Biochem Behav, 9, 753-758.

Martyn, C. N., Illis, L. S. \& Thom, J. (1995). Nabilone in the treatment of multiple sclerosis. Lancet, 345, 579.

Mason, R. \& Cheer, J. F. (2009). Cannabinoid receptor activation reverses kainate-induced synchronized population burst firing in rat hippocampus. Front Integr Neurosci, 3, 13.

Matsuda, L. A., Lolait, S. J., Brownstein, M. J., Young, A. C. \& Bonner, T. I. (1990). Structure of a cannabinoid receptor and functional expression of the cloned cDNA. Nature, 346, 561-564. 
Mcgrath, P. (2002). Reflections on nutritional issues associated with cancer therapy. Cancer Pract, 10, 94-101.

McMeens, R. R. (1856). Cannabis indica in convulsions. Western Lancet, 327-331.

McMeens, R. R. (1860). Report of the Ohio State Medical Committee on Cannabis indica, White Sulphur Springs, OH, Ohio State Medical Society.

Mechoulam, R. 1986. The pharmacohistory of Cannabis sativa, Boca Raton, FL, CRC Press.

Mechoulam, R. (2005). Plant cannabinoids: a neglected pharmacological treasure trove. $\mathrm{Br} \mathrm{J}$ Pharmacol, 146, 913-915.

Mechoulam, R., Ben-Shabat, S., Hanus, L., Ligumsky, M., Kaminski, N. E., Schatz, A. R., et al. (1995). Identification of an endogenous 2-monoglyceride, present in canine gut, that binds to cannabinoid receptors. Biochem Pharmacol, 50, 83-90.

Mechoulam, R., Shani, A., Edery, H. \& Grunfeld, Y. (1970). Chemical basis of hashish activity. Science, 169, 611-612.

Mehmedic, Z., Chandra, S., Slade, D., Denham, H., Foster, S., Patel, A. S., et al. (2010). Potency trends of Delta9-THC and other cannabinoids in confiscated cannabis preparations from 1993 to 2008. J Forensic Sci, 55, 1209-1217.

Meschler, J. P., Howlett, A. C. \& Madras, B. K. (2001). Cannabinoid receptor agonist and antagonist effects on motor function in normal and 1-methyl-4-phenyl-1,2,5,6tetrahydropyridine (MPTP)-treated non-human primates. Psychopharmacology (Berl), $156,79-85$.

Moffat, A. C. (2002). The legalization of Cannabis for medical use. Sci Justice, 42, 55-57.

Monory, K., Massa, F., Egertova, M., Eder, M., Blaudzun, H., Westenbroek, R., et al. (2006). The endocannabinoid system controls key epileptogenic circuits in the hippocampus. Neuron, 51, 455-466.

Moreira, F. A., Aguiar, D. C. \& Guimaraes, F. S. (2006). Anxiolytic-like effect of cannabidiol in the rat Vogel conflict test. Prog Neuropsychopharmacol Biol Psychiatry, 30, 1466-1471.

Morris, J. \& Volicer, L. (2001). Nutritional management of individuals with Alzheimer's disease and other progressive dementias. Nutr Clin Care, 4, 148-155. 
Mortati, K., Dworetzky, B. \& Devinsky, O. (2007). Marijuana: an effective antiepileptic treatment in partial epilepsy? A case report and review of the literature. Rev Neurol Dis, 4, 103-106.

Munro, S., Thomas, K. L. \& Abu-Shaar, M. (1993). Molecular characterization of a peripheral receptor for cannabinoids. Nature, 365, 61-65.

Musty, R. \& Deyo, R. (2006). A cannabigerol (CBC) extract alters behavioral dispair in an animal model of depression. $16^{\text {th }}$ Annual Symposium on the Cannabinoids, International Cannabinoid Research Society, Burlington, VT, p.32.

Nevalainen, T. \& Irving, A. J. (2010). GPR55, a lysophosphatidylinositol receptor with cannabinoid sensitivity? Curr Top Med Chem, 10, 799-813.

Ng, S. K., Brust, J. C., Hauser, W. A. \& Susser, M. (1990). Illicit drug use and the risk of newonset seizures. Am J Epidemiol, 132, 47-57.

Notcutt, W., Price, M., Chapman, G. (1997). Clinical experience with nabilone for chronic pain. Pharmaceutical Sci, 3, 551-555.

Novotna, A., Mares, J., Ratcliffe, S., Novakova, I., Vachova, M., Zapletalova, O., et al. (2011). A randomized, double-blind, placebo-controlled, parallel-group, enriched-design study of nabiximols* (Sativex((R)) ), as add-on therapy, in subjects with refractory spasticity caused by multiple sclerosis. Eur J Neurol.

Nunez, E., Benito, C., Pazos, M. R., Barbachano, A., Fajardo, O., Gonzalez, S., et al. (2004). Cannabinoid CB2 receptors are expressed by perivascular microglial cells in the human brain: an immunohistochemical study. Synapse, 53, 208-213.

O'Shaughnessy, W. B. (1840). On the preparations of the Indian hemp, or gunjah (Cannabis indica). Transactions of the Medical and Physical Society of Bengal, 71-102.

Onaivi, E. S., Ishiguro, H., Gong, J. P., Patel, S., Perchuk, A., Meozzi, P. A., et al. (2006). Discovery of the presence and functional expression of cannabinoid CB2 receptors in brain. Ann N Y Acad Sci, 1074, 514-536.

Oz, M. (2006). Receptor-independent actions of cannabinoids on cell membranes: focus on endocannabinoids. Pharmacol Ther, 111, 114-144. 
Pagotto, U., Marsicano, G., Cota, D., Lutz, B. \& Pasquali, R. (2006). The emerging role of the endocannabinoid system in endocrine regulation and energy balance. Endocr Rev, 27, 73100.

Parolaro, D., Realini, N., Vigano, D., Guidali, C. \& Rubino, T. (2010). The endocannabinoid system and psychiatric disorders. Exp Neurol, 224, 3-14.

Patel, S. \& Hillard, C. J. (2001). Cannabinoid CB(1) receptor agonists produce cerebellar dysfunction in mice. J Pharmacol Exp Ther, 297, 629-637.

Patricelli, M. P. \& Cravatt, B. F. (2001). Characterization and manipulation of the acyl chain selectivity of fatty acid amide hydrolase. Biochemistry, 40, 6107-6115.

Paulson, H. L. (2009). The spinocerebellar ataxias. J Neuroophthalmol, 29, 227-237.

Perl, D. P. (2010). Neuropathology of Alzheimer's disease. Mt Sinai J Med, 77, 32-42.

Perras, C. (2005). Sativex for the management of multiple sclerosis symptoms. Issues Emerg Health Technol, 1-4.

Pertwee, R. G. (2007). GPR55: a new member of the cannabinoid receptor clan? Br J Pharmacol, 152, 984-986.

Pertwee, R. G. (2008). The diverse CB1 and CB2 receptor pharmacology of three plant cannabinoids: delta9-tetrahydrocannabinol, cannabidiol and delta9tetrahydrocannabivarin. Br J Pharmacol, 153, 199-215.

Pertwee, R. G., Howlett, A. C., Abood, M. E., Alexander, S. P., Di Marzo, V., Elphick, M. R., et al. (2010). International Union of Basic and Clinical Pharmacology. LXXIX. Cannabinoid receptors and their ligands: beyond CB and CB. Pharmacol Rev, 62, 588631.

Pertwee, R. G., Ross, R. A., Craib, S. J. \& Thomas, A. (2002). (-)-Cannabidiol antagonizes cannabinoid receptor agonists and noradrenaline in the mouse vas deferens. Eur $J$ Pharmacol, 456, 99-106.

Petro, D. J. (1997). Seizure Disorders, Jefferson, NC, McFarland and Co.

Pistovcakova, J., Sulcova, A., et al.. (2006). Comparison of the effects of cannabidiol in two mouse models of depression. In Collegium Internationale Neuro Psychopharmacologicum - Book of Abstracts. Tallinn, Estonia: CINP, 56 -56. 
Pijlman, F. T., Rigter, S. M., Hoek, J., Goldschmidt, H. M. \& Niesink, R. J. (2005). Strong increase in total delta-THC in cannabis preparations sold in Dutch coffee shops. Addict Biol, 10, 171-180.

Plasse, T. F., Gorter, R. W., Krasnow, S. H., Lane, M., Shepard, K. V. \& Wadleigh, R. G. (1991). Recent clinical experience with dronabinol. Pharmacol Biochem Behav, 40, 695-700.

Price, M. R., Baillie, G. L., Thomas, A., Stevenson, L. A., Easson, M., Goodwin, R., et al. (2005). Allosteric modulation of the cannabinoid CB1 receptor. Mol Pharmacol, 68, 1484-1495.

Qian, L., Flood, P. M. \& Hong, J. S. (2010). Neuroinflammation is a key player in Parkinson's disease and a prime target for therapy. J Neural Transm, 117, 971-979.

Qin, N., Neeper, M. P., Liu, Y., Hutchinson, T. L., Lubin, M. L. \& Flores, C. M. (2008). TRPV2 is activated by cannabidiol and mediates CGRP release in cultured rat dorsal root ganglion neurons. J Neurosci, 28, 6231-6238.

Rakhshan, F., Day, T. A., Blakely, R. D. \& Barker, E. L. (2000). Carrier-mediated uptake of the endogenous cannabinoid anandamide in RBL-2H3 cells. J Pharmacol Exp Ther, 292, 960-967.

Ramirez, B. G., Blazquez, C., Gomez Del Pulgar, T., Guzman, M. \& De Ceballos, M. L. (2005). Prevention of Alzheimer's disease pathology by cannabinoids: neuroprotection mediated by blockade of microglial activation. J Neurosci, 25, 1904-1913.

Regelson, W., Butler, J. R. (1976). $\Delta^{9}$-THC as an effective antidepressant and appetite stimulating agent in advanced cancer patients. In Braude M C, Szara S (eds), The Pharmacology of Marihuana. Raven Press, New York, NY, 763-776.

Reilly, D., Didcott, P., Swift, W. \& Hall, W. (1998). Long-term cannabis use: characteristics of users in an Australian rural area. Addiction, 93, 837-846.

Resstel, L. B., Joca, S. R., Moreira, F. A., Correa, F. M. \& Guimaraes, F. S. (2006). Effects of cannabidiol and diazepam on behavioral and cardiovascular responses induced by contextual conditioned fear in rats. Behav Brain Res, 172, 294-298.

Resstel, L. B., Tavares, R. F., Lisboa, S. F., Joca, S. R., Correa, F. M. \& Guimaraes, F. S. (2009). 5-HT1A receptors are involved in the cannabidiol-induced attenuation of behavioural and cardiovascular responses to acute restraint stress in rats. Br J Pharmacol, 156, 181-188. 
Reynolds, J. R. (1868). Therapeutical uses and toxic effects of Cannabis indica. Lancet, 1, 637638.

Riedel, G., Fadda, P., Mckillop-Smith, S., Pertwee, R. G., Platt, B. \& Robinson, L. (2009). Synthetic and plant-derived cannabinoid receptor antagonists show hypophagic properties in fasted and non-fasted mice. Br J Pharmacol, 156, 1154-1166.

Rivers, J. R. \& Ashton, J. C. (2010). The development of cannabinoid CBII receptor agonists for the treatment of central neuropathies. Cent Nerv Syst Agents Med Chem, 10, 47-64.

Robson, P. (2001). Therapeutic aspects of cannabis and cannabinoids. Br J Psychiatry, 178, 107115.

Rog, D. J. (2010). Cannabis-based medicines in multiple sclerosis--a review of clinical studies. Immunobiology, 215, 658-672.

Rog, D. J., Nurmikko, T. J., Friede, T. \& Young, C. A. (2005). Randomized, controlled trial of cannabis-based medicine in central pain in multiple sclerosis. Neurology, 65, 812-819.

Rog, D. J., Nurmikko, T. J. \& Young, C. A. (2007). Oromucosal delta9tetrahydrocannabinol/cannabidiol for neuropathic pain associated with multiple sclerosis: an uncontrolled, open-label, 2-year extension trial. Clin Ther, 29, 2068-2079.

Ross, H. R., Napier, I. \& Connor, M. (2008). Inhibition of recombinant human T-type calcium channels by Delta9-tetrahydrocannabinol and cannabidiol. J Biol Chem, 283, 1612416134.

Ross, R. A. (2009). The enigmatic pharmacology of GPR55. Trends Pharmacol Sci, 30, 156-163.

Ruiz-Valdepenas, L., Martinez-Orgado, J. A., Benito, C., Millan, A., Tolon, R. M. \& Romero, J. (2011). Cannabidiol reduces lipopolysaccharide-induced vascular changes and inflammation in the mouse brain: an intravital microscopy study. J Neuroinflammation, 8, 5.

Russo, E. B. (2005). Cannabis in India: Ancient lore and modern medicine. In: Mechoulam R. (ed.), Cannabinoids as therapeutics, Birkhäuser Verlag, Basel, Switzerland 1-22.

Russo, E. \& Guy, G. W. (2006). A tale of two cannabinoids: the therapeutic rationale for combining tetrahydrocannabinol and cannabidiol. Med Hypotheses, 66, 234-246.

Russo, E. B. (2007). History of cannabis and its preparations in saga, science, and sobriquet. Chem Biodivers, 4, 1614-1648. 
Russo, E. B. (2011). Taming THC: potential cannabis synergy and phytocannabinoid-terpenoid entourage effects. Br J Pharmacol, 163, 1344-1364.

Russo, E. B., Burnett, A., Hall, B. \& Parker, K. K. (2005). Agonistic properties of cannabidiol at 5-HT1a receptors. Neurochem Res, 30, 1037-1043.

Ryan, D., Drysdale, A. J., Lafourcade, C., Pertwee, R. G. \& Platt, B. (2009). Cannabidiol targets mitochondria to regulate intracellular Ca2+ levels. J Neurosci, 29, 2053-2063.

Saban, A., Flisher, A. J. \& Distiller, G. (2010). Association between psychopathology and substance use among school-going adolescents in Cape Town, South Africa. $J$ Psychoactive Drugs, 42, 467-476.

Sacks, N., Hutcheson, J. R., Jr., Watts, J. M. \& Webb, R. E. (1990). Case report: the effect of tetrahydrocannabinol on food intake during chemotherapy. J Am Coll Nutr, 9, 630-632.

Sagredo, O., Ramos, J. A., Decio, A., Mechoulam, R. \& Fernandez-Ruiz, J. (2007). Cannabidiol reduced the striatal atrophy caused 3-nitropropionic acid in vivo by mechanisms independent of the activation of cannabinoid, vanilloid TRPV1 and adenosine A2A receptors. Eur J Neurosci, 26, 843-851.

Sandyk, R., Snider, S. R., Consroe, P. \& Elias, S. M. (1986). Cannabidiol in dystonic movement disorders. Psychiatry Res, 18, 291.

Schoedel, K.A., Chen, N., Hilliard, A., White, L., Stott, C., Russo, E., et al. (2011). A randomized, double-blind, placebo-controlled, crossover study to evaluate the abuse potential of nabiximols oromucosal spray in subjects with a history of recreational cannabis use. Hum Psychopharmacol, Jun 13 [Epub ahead of print]

Scopinho, A. A., Guimaraes, F. S., Correa, F. M. \& Resstel, L. B. (2011). Cannabidiol inhibits the hyperphagia induced by cannabinoid-1 or serotonin-1A receptor agonists. Pharmacol Biochem Behav, 98, 268-272.

Sharir, H. \& Abood, M. E. (2010). Pharmacological characterization of GPR55, a putative cannabinoid receptor. Pharmacol Ther, 126, 301-313.

Shen, M. \& Thayer, S. A. (1999). Delta9-tetrahydrocannabinol acts as a partial agonist to modulate glutamatergic synaptic transmission between rat hippocampal neurons in culture. Mol Pharmacol, 55, 8-13. 
Shou-Zhong, Y. (1997). The divine farmer as materia medica: A translation of the Shen Nong Ben Cao Jing. Blue Poppy Press, Boulder, CO, p. 198.

Sieradzan, K. A., Fox, S. H., Hill, M., Dick, J. P., Crossman, A. R. \& Brotchie, J. M. (2001). Cannabinoids reduce levodopa-induced dyskinesia in Parkinson's disease: a pilot study. Neurology, 57, 2108-2111.

Silverdale, M. A., Mcguire, S., Mcinnes, A., Crossman, A. R. \& Brotchie, J. M. (2001). Striatal cannabinoid $\mathrm{CB} 1$ receptor mRNA expression is decreased in the reserpine-treated rat model of Parkinson's disease. Exp Neurol, 169, 400-406.

Skolnick, P., Legutko, B., Li, X. \& Bymaster, F. P. (2001). Current perspectives on the development of non-biogenic amine-based antidepressants. Pharmacol Res, 43, 411-423.

Smiley, K. A., Karler, R. \& Turkanis, S. A. (1976). Effects of cannabinoids on the perfused rat heart. Res Commun Chem Pathol Pharmacol, 14, 659-675.

Sofia, R. D. \& Knobloch, L. C. (1976). Comparative effects of various naturally occurring cannabinoids on food, sucrose and water consumption by rats. Pharmacol Biochem Behav, 4, 591-599.

Stadelmann, C., Wegner, C. \& Bruck, W. (2011). Inflammation, demyelination, and degeneration - recent insights from MS pathology. Biochim Biophys Acta, 1812, 275-282.

Stella, N. (2010). Cannabinoid and cannabinoid-like receptors in microglia, astrocytes, and astrocytomas. Glia, 58, 1017-1030.

Strasser, F., Luftner, D., Possinger, K., Ernst, G., Ruhstaller, T., Meissner, W., et al. (2006). Comparison of orally administered cannabis extract and delta-9-tetrahydrocannabinol in treating patients with cancer-related anorexia-cachexia syndrome: a multicenter, phase III, randomized, double-blind, placebo-controlled clinical trial from the Cannabis-InCachexia-Study-Group. J Clin Oncol, 24, 3394-3400.

Sugiura, T., Kondo, S., Sukagawa, A., Nakane, S., Shinoda, A., Itoh, K., et al. (1995). 2 Arachidonoylglycerol: a possible endogenous cannabinoid receptor ligand in brain. Biochem Biophys Res Commun, 215, 89-97.

Svendsen, K. B., Jensen, T. S. \& Bach, F. W. (2004). Does the cannabinoid dronabinol reduce central pain in multiple sclerosis? Randomised double blind placebo controlled crossover trial. BMJ, 329, 253. 
Thomas, A., Baillie, G. L., Phillips, A. M., Razdan, R. K., Ross, R. A. \& Pertwee, R. G. (2007). Cannabidiol displays unexpectedly high potency as an antagonist of CB1 and CB2 receptor agonists in vitro. Br J Pharmacol, 150, 613-623.

Thomas, A., Stevenson, L. A., Wease, K. N., Price, M. R., Baillie, G., Ross, R. A., et al. (2005). Evidence that the plant cannabinoid Delta(9)-tetrahydrocannabivarin is a cannabinoid $\mathrm{CB}(1)$ and $\mathrm{CB}(2)$ receptor antagonist. Br J Pharmacol.

Thomson, T. D. \& Turkanis, S. A. (1973). Barbiturate-induced transmitter release at a frog neuromuscular junction. British Journal of Pharmacology, 48, 48-58.

Tourino, C., Zimmer, A. \& Valverde, O. (2010). THC Prevents MDMA Neurotoxicity in Mice. PLoS One, 5, e9143.

Touw, M. (1981). The religious and medicinal uses of Cannabis in China, India and Tibet. $J$ Psychoactive Drugs, 13, 23-34.

Trembly, B. \& Sherman, M. (1990). Double-blind clinical study of cannabidiol as a secondary anticonvulsant. Marijuana '90 International Conference on Cannabis and Cannabinoids. Kolympari, Crete, July 8-11.

Tsou, K., Brown, S., Sanudo-Pena, M. C., Mackie, K. \& Walker, J. M. (1998). Immunohistochemical distribution of cannabinoid CB1 receptors in the rat central nervous system. Neuroscience, 83, 393-411.

Turkanis, S. A., Cely, W., Olsen, D. M. \& Karler, R. (1974). Anticonvulsant properties of cannabidiol. Res Commun Chem Pathol Pharmacol, 8, 231-246.

Turkanis, S. A., Chiu, P., Borys, H. K. \& Karler, R. (1977). Influence of delta9tetrahydrocannabinol and cannabidiol on photically evoked after-discharge potentials. Psychopharmacology (Berl), 52, 207-212.

Turkanis, S. A. \& Karler, R. (1975). Influence of anticonvulsant cannabinoids on posttetanic potentiation at isolated bullfrog ganglia. Life Sci, 17, 569-578.

Turkanis, S. A. \& Karler, R. (1981a). Electrophysiologic properties of the cannabinoids. J Clin Pharmacol, 21, 449S-463S.

Turkanis, S. A. \& Karler, R. (1981b). Excitatory and depressant effects of delta 9tetrahydrocannabinol and cannabidiol on cortical evoked responses in the conscious rat. Psychopharmacology (Berl), 75, 294-298. 
Turkanis, S. A. \& Karler, R. (1982). Central excitatory properties of delta 9tetrahydrocannabinol and its metabolites in iron-induced epileptic rats. Neuropharmacology, 21, 7-13.

Turkanis, S. A. \& Karler, R. (1987). Different cannabinoids exhibit different electrophysiological properties. NIDA Res Monogr, 79, 67-81.

Turkanis, S. A., Karler, R. \& Partlow, L. M. (1991). Differential effects of delta-9tetrahydrocannabinol and its 11-hydroxy metabolite on sodium current in neuroblastoma cells. Brain Res, 560, 245-250.

Turkanis, S. A., Smiley, K. A., Borys, H. K., Olsen, D. M. \& Karler, R. (1979). An electrophysiological analysis of the anticonvulsant action of cannabidiol on limbic seizures in conscious rats. Epilepsia, 20, 351-363.

Van Der Stelt, M., Veldhuis, W. B., Bar, P. R., Veldink, G. A., Vliegenthart, J. F. \& Nicolay, K. (2001). Neuroprotection by Delta9-tetrahydrocannabinol, the main active compound in marijuana, against ouabain-induced in vivo excitotoxicity. J Neurosci, 21, 6475-6479.

Van Rossum, I., Boomsma, M., Tenback, D., Reed, C. \& Van Os, J. (2009). Does cannabis use affect treatment outcome in bipolar disorder? A longitudinal analysis. J Nerv Ment Dis, $197,35-40$.

Van Sickle, M. D., Duncan, M., Kingsley, P. J., Mouihate, A., Urbani, P., Mackie, K., et al. (2005). Identification and functional characterization of brainstem cannabinoid CB2 receptors. Science, 310, 329-332.

Van Vliet, S. A., Vanwersch, R. A., Jongsma, M. J., Olivier, B. \& Philippens, I. H. (2008). Therapeutic effects of Delta9-THC and modafinil in a marmoset Parkinson model. Eur Neuropsychopharmacol, 18, 383-389.

Vaney, C., Heinzel-Gutenbrunner, M., Jobin, P., Tschopp, F., Gattlen, B., Hagen, U., et al. (2004). Efficacy, safety and tolerability of an orally administered cannabis extract in the treatment of spasticity in patients with multiple sclerosis: a randomized, double-blind, placebo-controlled, crossover study. Mult Scler, 10, 417-424.

Vann, R. E., Gamage, T. F., Warner, J. A., Marshall, E. M., Taylor, N. L., Martin, B. R., et al. (2008). Divergent effects of cannabidiol on the discriminative stimulus and place 
conditioning effects of Delta(9)-tetrahydrocannabinol. Drug Alcohol Depend, 94, 191198.

Venderová, K., Růzicka, E., Vorísek, V., Visnovský, P. (2004). Survey on cannabis use in Parkinson's disease: Subjective improvement of motor symptoms. Mov Disord, 19, 11021106.

Volicer, L (1997). Dronabinol may help behaviour problems in Alzheimers disease. Amer Family Phys, 55, 1338.

Wade, D. T., Makela, P., Robson, P., House, H. \& Bateman, C. (2004). Do cannabis-based medicinal extracts have general or specific effects on symptoms in multiple sclerosis? A double-blind, randomized, placebo-controlled study on 160 patients. Mult Scler, 10, 434441.

Wade, D. T., Makela, P. M., House, H., Bateman, C. \& Robson, P. (2006). Long-term use of a cannabis-based medicine in the treatment of spasticity and other symptoms in multiple sclerosis. Mult Scler, 12, 639-645.

Wade, D. T., Robson, P., House, H., Makela, P. \& Aram, J. (2003). A preliminary controlled study to determine whether whole-plant cannabis extracts can improve intractable neurogenic symptoms. Clin Rehabil, 17, 21-29.

Wallace, M. J., Wiley, J. L., Martin, B. R. \& Delorenzo, R. J. (2001). Assessment of the role of CB1 receptors in cannabinoid anticonvulsant effects. Eur J Pharmacol, 428, 51-57.

Walsh, S., Mnich, K., Mackie, K., Gorman, A. M., Finn, D. P. \& Dowd, E. (2010). Loss of cannabinoid CB1 receptor expression in the 6-hydroxydopamine-induced nigrostriatal terminal lesion model of Parkinson's disease in the rat. Brain Res Bull, 81, 543-548.

Walther, S., Mahlberg, R., Eichmann, U. \& Kunz, D. (2006). Delta-9-tetrahydrocannabinol for nighttime agitation in severe dementia. Psychopharmacology (Berl), 185, 524-528.

Wang, X., Horswill, J. G., Whalley, B. J. \& Stephens, G. J. (2011). Effects of the Allosteric Antagonist 1-(4-Chlorophenyl)-3-[3-(6-pyrrolidin-1-ylpyridin-2-yl)phenyl]urea (PSNCBAM-1) on CB1 Receptor Modulation in the Cerebellum. Mol Pharmacol, 79, $758-767$. 
Watanabe, K., Kayano, Y., Matsunaga, T., Yamamoto, I. \& Yoshimura, H. (1996). Inhibition of anandamide amidase activity in mouse brain microsomes by cannabinoids. Biol Pharm Bull, 19, 1109-1111.

Whalley, B. J., Wilkinson, J. D., Williamson, E. M. \& Constanti, A. (2004). A novel component of cannabis extract potentiates excitatory synaptic transmission in rat olfactory cortex in vitro. Neuroscience Letters, 365, 58-63.

Whitton, P. S. (2010). Neuroinflammation and the prospects for anti-inflammatory treatment of Parkinson's disease. Curr Opin Investig Drugs, 11, 788-794.

Wiley, J. L., Burston, J. J., Leggett, D. C., Alekseeva, O. O., Razdan, R. K., Mahadevan, A., et al. (2005). CB1 cannabinoid receptor-mediated modulation of food intake in mice. $\mathrm{Br} J$ Pharmacol, 145, 293-300.

Wilkinson, J. D., Whalley, B. J., Baker, D., Pryce, G., Constanti, A., Gibbons, S., et al. (2003). Medicinal cannabis: is delta9-tetrahydrocannabinol necessary for all its effects? Journal of Pharmacy and Pharmacology, 55, 1687-1694.

Williams, C. M. \& Kirkham, T. C. (2002a). Observational analysis of feeding induced by Delta9-THC and anandamide. Physiol Behav, 76, 241-250.

Williams, C. M. \& Kirkham, T. C. (2002b). Reversal of delta 9-THC hyperphagia by SR141716 and naloxone but not dexfenfluramine. Pharmacol Biochem Behav, 71, 333-340.

Williams, C. M., Rogers, P. J. \& Kirkham, T. C. (1998). Hyperphagia in pre-fed rats following oral delta9-THC. Physiol Behav, 65, 343-346.

Wilson, M. M., Philpot, C. \& Morley, J. E. (2007). Anorexia of aging in long term care: is dronabinol an effective appetite stimulant?--a pilot study. J Nutr Health Aging, 11, 195198.

Yang, K. H., Galadari, S., Isaev, D., Petroianu, G., Shippenberg, T. S. \& Oz, M. (2010). The nonpsychoactive cannabinoid cannabidiol inhibits 5-hydroxytryptamine3A receptormediated currents in Xenopus laevis oocytes. J Pharmacol Exp Ther, 333, 547-554.

Zajicek, J., Fox, P., Sanders, H., Wright, D., Vickery, J., Nunn, A., et al. (2003). Cannabinoids for treatment of spasticity and other symptoms related to multiple sclerosis (CAMS study): multicentre randomised placebo-controlled trial. Lancet, 362, 1517-1526. 
Zajicek, J. P., Sanders, H. P., Wright, D. E., Vickery, P. J., Ingram, W. M., Reilly, S. M., et al. (2005). Cannabinoids in multiple sclerosis (CAMS) study: safety and efficacy data for 12 months follow up. J Neurol Neurosurg Psychiatry, 76, 1664-1669.

Zanelati, T. V., Biojone, C., Moreira, F. A., Guimaraes, F. S. \& Joca, S. R. (2010). Antidepressant-like effects of cannabidiol in mice: possible involvement of 5-HT1A receptors. Br J Pharmacol, 159, 122-128.

Zani, A., Braida, D., Capurro, V. \& Sala, M. (2007). Delta9-tetrahydrocannabinol (THC) and AM 404 protect against cerebral ischaemia in gerbils through a mechanism involving cannabinoid and opioid receptors. Br J Pharmacol, 152, 1301-1311.

Zuardi, A., Crippa, J., Dursun, S., Morais, S., Vilela, J., Sanches, R., et al. (2010). Cannabidiol was ineffective for manic episode of bipolar affective disorder. J Psychopharmacol, 24, 135-137.

Zuardi, A. W., Crippa, J. A., Hallak, J. E., Moreira, F. A. \& Guimaraes, F. S. (2006). Cannabidiol, a Cannabis sativa constituent, as an antipsychotic drug. Braz J Med Biol Res, 39, 421-429.

Zuardi, A. W., Crippa, J. A., Hallak, J. E., Pinto, J. P., Chagas, M. H., Rodrigues, G. G., et al. (2009). Cannabidiol for the treatment of psychosis in Parkinson's disease. $J$ Psychopharmacol, 23, 979-983.

Zuardi, A. W., Guimaraes, F. S. \& Moreira, A. C. (1993). Effect of cannabidiol on plasma prolactin, growth hormone and cortisol in human volunteers. Braz J Med Biol Res, 26, 213-217.

Zuardi, A. W. \& Karniol, I. G. (1983). Effects on variable-interval performance in rats of delta 9tetrahydrocannabinol and cannabidiol, separately and in combination. Braz J Med Biol Res, 16, 141-146.

Zuardi, A. W., Shirakawa, I., Finkelfarb, E. \& Karniol, I. G. (1982). Action of cannabidiol on the anxiety and other effects produced by delta 9-THC in normal subjects. Psychopharmacology (Berl), 76, 245-250. 